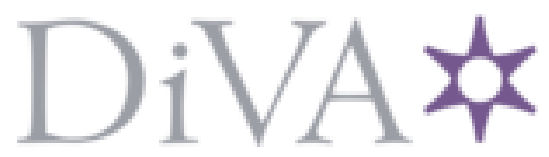

http://www.diva-portal.org

\title{
Preprint
}

This is the submitted version of a paper published in Bioconjugate chemistry.

Citation for the original published paper (version of record):

Varasteh, Z., Velikyan, I., Lindeberg, G., Sörensen, J., Larhed, M. et al. (2013)

Synthesis and Characterization of a High-Affinity NOTA-Conjugated Bombesin Antagonist for GRPR-Targeted Tumor Imaging.

Bioconjugate chemistry, 24(7): 1144-1153

http://dx.doi.org/10.1021/bc300659k

Access to the published version may require subscription.

N.B. When citing this work, cite the original published paper.

Permanent link to this version:

http://urn.kb.se/resolve?urn=urn:nbn:se:uu:diva-20704 1 
"This document is the unedited Author's version of a Submitted Work that was subsequently accepted for publication in Bioconjugate Chemistry copyright $@$ American Chemical Society after peer review. To access the final edited and published work see [insert ACS Articles on Request author-directed link to Published Work, see http://pubs.acs.org/page/policy/articlesonrequest/index.html]."”

\section{Synthesis and characterization of a high affinity NOTA-conjugated bombesin antagonist for GRPR-targeted tumor imaging}

Zohreh Varasteh ${ }^{\dagger}$, Irina Velikyan ${ }^{\dagger, \ddagger}$, Gunnar Lindeberg ${ }^{\#}$, Jens Sörensen ${ }^{\ddagger}$, , Mats Larhed ${ }^{\#}$, Mattias Sandström ${ }^{\S}$, Ram Kumar Selvaraju ${ }^{\dagger}$, Jennie Malmberg ${ }^{\dagger}$, Vladimir Tolmachev ${ }^{\star}$, Anna Orlova $^{\dagger *}$

$\dagger$ Preclinical PET Platform, Department of Medicinal Chemistry, Faculty of Pharmacy, Uppsala university, Uppsala, Sweden

\$ Biomedical Radiation Sciences, Department of Radiology, Oncology and Radiation Science, Faculty of Medicine, Uppsala University, Uppsala, Sweden

\# Organic Pharmaceutical Chemistry, Department of Medicinal Chemistry, Faculty of Pharmacy, Uppsala University, Uppsala, Sweden

§ PET Centrum, Uppsala University Hospital, Uppsala, Sweden

*Corresponding author:

Anna Orlova, anna.orlova@pet.medchem.uu.se,

Preclinical PET Platform, Department of Medicinal Chemistry, Faculty of Pharmacy, Uppsala University, Uppsala, Sweden

Fax: +46(0)18 471 5307, Phone: +46(0)73 9922 846,

Dag Hammarskjöldsv 14C, 3 tr, 75183 Uppsala, Sweden.

Key words: Bombesin analog, GRPR, Gallium-68. Indium-111, Antagonist, Molecular imaging, prostate cancer, PC-3 cells 


\section{ABSTRACT}

Gastrin releasing peptide receptor (GRPR/BB2) is a molecular target for visualization of prostate cancer. This work is focused on the development of high affinity hydrophilic antagonistic bombesin-based imaging agents for PET and SPECT. A bombesin antagonist analog (D-Phe-GlnTrp-Ala-Val-Gly-His-Sta-Leu-NH $2,\left[\mathrm{D}-\mathrm{Phe}^{6}, \mathrm{Sta}^{13}, \mathrm{Leu}^{14}\right]$ bombesin[6-14]) was synthesized and conjugated to 1,4,7-triazacyclononane-N,N',N"-triacetic acid (NOTA) via diethylene glycol $\left(\mathrm{PEG}_{2}\right)$ linker. Resulting conjugate, NOTA-PEG $2-\left[\mathrm{D}-\mathrm{Phe}^{6}, \mathrm{Sta}^{13}, \mathrm{Leu}^{14}\right]$ bombesin[6-14] (NOTA$\mathrm{P} 2-\mathrm{RM} 26)$, was labeled with ${ }^{68} \mathrm{Ga}\left(\mathrm{T}_{1 / 2}=68 \mathrm{~min}\right.$, positron emitter $)$ and ${ }^{111} \mathrm{In}\left(\mathrm{T}_{1 / 2}=2.8\right.$ days, gamma emitter). Labeling stability, specificity, inhibition efficiency $\left(\mathrm{IC}_{50}\right)$ and binding affinity $\left(\mathrm{K}_{\mathrm{D}}\right)$ to GRPRs of both labeled compounds, and their cellular retention and internalization were investigated. Pharmacokinetics of the dual isotope ${ }^{111} \mathrm{In} /{ }^{68} \mathrm{Ga}$-labeled peptide in NMRI as well as PC-3 tumor bearing mice has been studied. NOTA-P2-RM26 was labeled with ${ }^{111}$ In and ${ }^{68} \mathrm{Ga}$ with radiochemical yield of $>98 \%$. The receptor mediated and high affinity $\left(\mathrm{K}_{\mathrm{D}}<36 \mathrm{pM}\right.$, for

${ }^{111}$ In-labeled compound) binding to GRPR-expressing cells was demonstrated. ${ }^{\text {nat }}$ In- and ${ }^{\text {nat }} \mathrm{Ga}-$ NOTA-P2-RM26 showed low nanomolar inhibition efficiency $\left(\mathrm{IC}_{50}=1.24 \pm 0.29 \mathrm{nM}\right.$ and $0.91 \pm 0.19 \mathrm{nM}$, respectively). The internalization rate of the radiolabeled conjugates was slow. Radiometal labeled tracers demonstrated rapid blood clearance via kidney and GRPR-specific uptake in pancreas in normal mice. Tumor targeting and biodistribution studies in mice bearing PC-3 xenografts displayed high and specific uptake in tumors $\left(8.1 \pm 0.4 \% \mathrm{ID} / \mathrm{g}\right.$ for ${ }^{68} \mathrm{Ga}$ and $5.7 \pm 0.3 \% \mathrm{ID} / \mathrm{g}$ for ${ }^{111} \mathrm{In}$ ) and high tumor-to-background ratios (tumor/blood $12 \pm 1$ for ${ }^{68} \mathrm{Ga}$ and $10 \pm 1$ for ${ }^{111} \mathrm{In}$ ) already $1 \mathrm{~h}$ p.i. of $45 \mathrm{pmol}$ of peptide. The xenografts were visualized by gamma and microPET cameras shortly after injection. The antagonistic bombesin analog NOTA-PEG $2_{2}$ D-Phe-Gln-Trp-Ala-Val-Gly-His-Sta-Leu-NH2 (NOTA-P2-RM26) is a promising candidate for 
prostate

cancer

imaging

using

PET

and SPECT/CT. 


\section{Introduction}

Prostate cancer is, in most cases, a slow-growing cancer and symptoms arise when the tumor has already spread out of the local gland. Patients often have metastatic disease at the time of diagnosis. ${ }^{1}$ Staging, detection of bone and soft tissue involvement, is essential for guiding optimal therapy. Selection of treatment options depends highly on the stage of the cancer. Radical prostatectomy and/or external radiation therapy are treatment modalities for early diagnosed locally confined prostate tumors whereas androgen deprivation therapy (ADT) is the first-line treatment for the palliation of symptomatic late stage prostate cancer which has already metastasized. $^{2,3}$

PC cells show tropism for bone which is one of the strongly preferred sites for spread of the disease. Bone scan using ${ }^{99 \mathrm{~m}} \mathrm{Tc}$-methylen diphosphonate, is the initial sensitive, cost and time efficient imaging modality for metastatic evaluation of $\mathrm{PC} .{ }^{4}$ Clinically, imaging of the soft tissue metastases remains a significant problem for staging of the disease.

Radionuclide-based molecular imaging can provide opportunities to obtain local information from prostate primary tumors as well as determining the extent of disease. Expression pattern of GRPR in PC suggests that this receptor can be an imaging target candidate for prostate cancer staging.

GRPR (also referred to as BB2) is a member of the bombesin receptor family in mammals, together with other members, neuromedin B receptor (NMBR/BB1), bombesin receptor subtype 3 (BB3) and subtype 4 (BB4, only in amphibians). Bombesin receptors are G-protein coupled receptors activated by $\mathrm{BN}$ and/or bombesin-like peptides. ${ }^{5} \mathrm{BN}$ that has two mammalian 
homologs, neuromedin B (NMB) ${ }^{6}$ and GRP, ${ }^{7}$ is a linear tetradecapeptide and has high affinity to GRPRs. BN-based tracer agonists have been extensively investigated in preclinical ${ }^{8,9}$ and clinical studies. ${ }^{10,11}$ All demonstrated high binding affinity to GRPRs and good radioligand internalization properties which are essential factors for optimal imaging. However, agonistbased bombesin analogs demonstrated strong physiological potency and mitogenicity even in trace amount as well as high and maintained uptake in the normal GRPR positive organs that resulted in poor contrast of images. To overcome these drawbacks BN antagonistic analogs with growth-inhibitory effect on tumors have been introduced. ${ }^{12,13}$ It was found that GRPR antagonists have more binding sites than agonists, which made them preferable for peptide receptor targeting of tumors. ${ }^{14}$ More binding sites for radioconjugates may enhance localization accuracy, especially in small lesions and tumors with low receptor-expression. High affinity and low dissociation rate are important contributors to the superiority of analogs with antagonistic function.

The aim of the present study was to develop a high affinity imaging agent for PC staging with optimal pharmacokinetics based on a nine amino acid residue bombesin analog D-Phe-Gln-TrpAla-Val-Gly-His-Sta-Leu- $\mathrm{NH}_{2}$ (RM26). ${ }^{13}$ The RM26 variants modified with DOTA as chelator and glycine-4-aminobenzoyl ${ }^{14}$ or 4-amino-1-carboxymethyl-piperidine ${ }^{15}$ as spacer has previously been investigated. In this study NOTA that forms stable complex with ${ }^{68} \mathrm{Ga}^{16}$ was coupled to the peptide via a synthetic polymer, diethylene glycol $\left(\mathrm{PEG}_{2}\right)$, in order to decrease the lipophilicity of the conjugate and modulate its pharmacokinetics. The peptide was labeled with radiometals suitable for PET and SPECT $\left({ }^{68} \mathrm{Ga}\right.$ and ${ }^{111}$ In, respectively). 


\section{Material and methods}

\section{Peptide synthesis:}

Bombesin analog NOTA-PEG 2 -[D-Phe $\left.{ }^{6}, \mathrm{Sta}^{13}, \mathrm{Leu}^{14}\right]$ bombesin[6-14] (further denoted as NOTAP2-RM26, see Chart) was synthesized by standard manual solid-phase peptide synthesis ${ }^{17}$ as described in Supplementary material 1.

\section{Radiolabeling and in vitro stability test:}

${ }^{68} \mathrm{Ge} /{ }^{68} \mathrm{Ga}$ generator (50 mCi, Obninsk, Eckert and Ziegler) was eluted with $1 \mathrm{~mL}$ fractions of 0.1 M HCl (Merck). Second fraction (200 MBq) was buffered with sodium acetate $(0.2 \mathrm{M})$ and sodium hydroxide $(0.04 \mathrm{M})$ to $\mathrm{pH}$ 4.2-4.6 followed by addition of NOTA-P2-RM26 (10 nmol). The mixture was incubated at $75^{\circ} \mathrm{C}$ for $10 \mathrm{~min}$. The crude product was analyzed by HPLC (Beckman) with UV and radioactivity detectors coupled in series using a column packed with SOURCE 15RPC chromatography polymeric medium (Resource RPC, 17-1181-01, GE Healthcare). Acquired data was analyzed by Beckman System Gold Nouveau Chromatography Software Package. The reaction mixture was also analyzed by radio-ITLC (Biodex Medical Systems) with running buffer of $0.2 \mathrm{M}$ citric acid, $\mathrm{pH} 2.0\left(\mathrm{R}_{f}=0.0\right.$ for peptide and $\mathrm{R}_{f}=1.0$ for free radiometal) and pyridine:acetic acid:water $(5: 3: 1.5)\left(\mathrm{R}_{f}=0.9\right.$ for peptide and $\mathrm{R}_{f}=0.0$ for free radiometal). The distribution of radioactivity on strips was measured with a Cyclone storage phosphor system and analyzed using the OptiQuant image analysis software (Perkin Elmer Sweden AB). 
For ${ }^{111}$ In-labeling, a solution of NOTA-P2-RM26 (10 nmol, $80 \mu 10.2 \mathrm{M}$ ammonium acetate (Merck), pH 5.5), was mixed with $60 \mathrm{MBq}(80-150 \mu \mathrm{L})$ of ${ }^{111} \mathrm{In}$ (Covidien) and incubated at $75^{\circ} \mathrm{C}$ for $30 \mathrm{~min}$. Buffers for ${ }^{111}$ In-labeling were purified from metal contamination by Chelex 100 resin (Bio-Rad Laboratories). The radio-ITLC analysis was performed for a small aliquot of reaction mixture as describe above.

For cold-isotope loading, $14 \mathrm{nmol}$ of ${ }^{\text {nat }} \mathrm{GaCl}_{3}$ or $13.5 \mathrm{nmol}$ of nat ${ }^{\mathrm{InCl}} \mathrm{n}_{3}$, aq. solution, (SigmaAldrich) were added to $10 \mathrm{nmol}$ of NOTA-P2-RM26 using the same protocols as radioactive isotopes.

To evaluate labeling stability, ${ }^{68}$ Ga-NOTA-P2-RM26 or ${ }^{111}$ In-NOTA-P2-RM26 were challenged with 500-fold molar excess of disodium salt of EDTA (Sigma) and incubated for $1 \mathrm{~h}$ at RT. The samples were analyzed by radio-ITLC. Additionally, samples were analyzed by SDS-PAGE. Free radiometals were applied as low molecular weight internal reference on the same gel.

For stability test in serum, $5 \mathrm{nmol}$ of the radiolabeled NOTA-P2-RM26 were incubated in $0.5 \mathrm{ml}$ murine serum at $37^{\circ} \mathrm{C}$ for $1 \mathrm{~h}$. The samples were analyzed by radio-ITLC.

\section{In vitro studies:}

GRPR expressing human prostate cancer cell line PC-3 (ATCC, LGC Standards AB) was cultured in RPMI media complemented with 10\% FCS, 2mM L-glutamine and PEST (penicillin $100 \mathrm{IU} / \mathrm{ml}$ ) (all from Biochrom AG). This media is referred to as complete media in the text. All experiments were performed in triplicate using $1-2 \times 10^{6}$ cells/dish.

The binding specificity of the radiolabeled NOTA-P2-RM26 on PC-3 cells was tested by incubation of the cells with $1 \mathrm{nM}$ concentration of the ${ }^{68} \mathrm{Ga}-$ or ${ }^{111} \mathrm{In}-\mathrm{NOTA}-\mathrm{P} 2-\mathrm{RM} 26$ solution 
for $2 \mathrm{~h}$ at $4^{\circ} \mathrm{C}$. To one set of dishes 100-fold excess of unlabeled NOTA-P2-RM26 was added 5 minutes before the addition of the ${ }^{68} \mathrm{Ga}$ - or ${ }^{111}$ In-NOTA-P2-RM26. After incubation, cells were detached by $0.5 \mathrm{ml} 25 \%$ trypsin/0.02\% EDTA solution in buffer (Biochrom AG) and collected. Cell associated radioactivity was measured in an automated $r$-counter with 3 -inch $\mathrm{NaI}(\mathrm{Tl})$ detector (1480 WIZARD, Wallac Oy).

To study cellular processing, cells were incubated at $37^{\circ} \mathrm{C}\left(5 \% \mathrm{CO}_{2}\right)$ with $1 \mathrm{nM}{ }^{111} \mathrm{In}-\mathrm{NOTA}-\mathrm{P} 2$ RM26 in complete medium. At predetermined time points, the membrane-bound and internalized radioactivity was estimated as described earlier. ${ }^{18}$ Internalization of ${ }^{68}$ Ga-NOTA-P2-RM26 and ${ }^{111}$ In-NOTA-P2-RM26 was compared with that of ${ }^{125} \mathrm{I}^{-T y r}{ }^{4}-\mathrm{BBN}$ (PerkinElmer) by analysis of internalized fraction for all conjugates after 30 min incubation of PC-3 cells with 2 nM solution of labeled conjugates at $37^{\circ} \mathrm{C}$.

In vitro competitive binding assay was performed using ${ }^{125} \mathrm{I}_{-} \mathrm{Tyr}^{4}-\mathrm{BBN}$. The half maximal inhibitory concentration $\left(\mathrm{IC}_{50}\right)$ was determined for non-radioactive, ${ }^{\text {nat }} \mathrm{Ga}$ - and ${ }^{\text {nat }}$ In-loaded conjugates. Cell monolayers were incubated for $5 \mathrm{~h}$ at $4^{\circ} \mathrm{C}$ with $0.1 \mathrm{pmol}$ of ${ }^{125} \mathrm{I}_{-\mathrm{Tyr}}{ }^{4}-\mathrm{BBN}$ in the presence of increasing concentrations of the competitors $\left(0-1 \times 10^{-6} \mathrm{M}\right)$. After incubation, cells were collected and their radioactivity was measured.

The binding of ${ }^{111}$ In-NOTA-P2-RM26 was measured in real-time at RT using LigandTracer Yellow (Ridgeview Instruments $A B$ ), as described previously. ${ }^{19,20}$ Two radioligand concentrations were used: 0.5 and $10 \mathrm{nM}$. Uptake was monitored for $200 \mathrm{~min}$ and retention for 1300 min. Interaction analysis and calculation of equilibrium dissociation constant $\left(\mathrm{K}_{\mathrm{D}}\right)$ was performed with TracerDrawer software (Ridgeview Instruments AB).

In other sets, cells were incubated with $20 \mathrm{nM}$ of ${ }^{68} \mathrm{Ga}-$ or ${ }^{111}$ In-NOTA-P2-RM26 at RT (LigandTracer Yellow) or $27 \mathrm{nM}$ of ${ }^{125} \mathrm{I}-\mathrm{Tyr}^{4}-\mathrm{BBN}$ at $4{ }^{\circ} \mathrm{C}$ (LigandTracer Grey). When 
radioactivity uptake reached saturation, cells were washed twice with serum-free media and after being trypsinized, detached cells were counted and collected for radioactivity measurement. Data were used for calculation of the available binding sites, $\mathrm{B}_{\max }$, on PC-3 cells for each of the compounds.

\section{In vivo studies:}

All animal experiments were planned and performed according to the national legislation on the protection of laboratory animals and study plans were approved by the local committee of animal research ethics. Groups of 4 mice per data point were used in all experiments. Biodistribution of ${ }^{68} \mathrm{Ga}-$ and ${ }^{111}$ In-labeled NOTA-P2-RM26 was evaluated in male NMRI mice (weight 33.1 $\pm 1.4 \mathrm{~g}$ ). $\mathrm{BALB} / \mathrm{c}$ nu/nu male mice bearing PC-3 xenografts $\left(5 \times 10^{6}\right.$ cells/mouse, implanted 3 weeks before the experiment) were used for in vivo targeting study (weight $21.4 \pm 1.0 \mathrm{~g}$ ). The average tumor size was $0.3 \pm 0.1 \mathrm{~g}$ at the time of the experiment.

Male NMRI mice were co-injected with 23 pmol of ${ }^{68} \mathrm{Ga} /{ }^{111} \mathrm{In}-\mathrm{NOTA}-\mathrm{P} 2-\mathrm{RM} 26$ (350 kBq of ${ }^{68} \mathrm{Ga}$ and $10 \mathrm{kBq}$ of ${ }^{111} \mathrm{In}, 100 \mu \mathrm{L}$ PBS) into the tail vein. In order to test the in vivo binding specificity, one group of animals was pre-injected intravenously with 20 nmol of unlabeled peptide $1 \mathrm{~h}$ before labeled-conjugate. The mice were euthanized at 1,2 , and $24 \mathrm{~h}$ p.i. by intraperitoneal injection of the Ketalar-Rompun solution $(10 \mathrm{mg} / \mathrm{mL}$ Ketalar and $1 \mathrm{mg} / \mathrm{mL}$ Rompun; $20 \mu \mathrm{L}$ of solution per gram of body weight). Blood samples were collected by heart puncture. Organs of interest were collected, weighed and their radioactivity content was measured in the gamma-counter. Whole gamma spectra were saved for the samples. One day after the first radioactivity measurement $\left({ }^{68} \mathrm{Ga}\right.$ radioactivity was decayed $)$, samples were remeasured for ${ }^{111}$ In radioactivity using the same protocol. Subtraction of the ${ }^{111}$ In decay-corrected radioactivity was considered as ${ }^{68} \mathrm{Ga}$ radioactivity. The organ uptake values were expressed as 
$\%$ ID/g except for the gastrointestinal tract and carcass, which were expressed as \%ID per whole sample.

To study influence of peptide dose on tumor uptake and pharmacokinetics, male Balb/c nu/nu mice bearing PC-3 xenografts were injected with ${ }^{111}$ In-NOTA-P2-RM26 (30 kBq, $100 \mu \mathrm{L}$ PBS). The administrated peptide dose was adjusted to 3.6, 15, 25 and 45 pmol/mouse by dilution with non-labeled NOTA-P2-RM26. The mice were sacrificed 2 h p.i. Radioactivity of blood and selected organs was measured using ${ }^{111}$ In protocol and expressed as described earlier.

To study tumor targeting, male BALB/c nu/nu mice bearing PC-3 xenografts were injected with 45 pmol of ${ }^{68} \mathrm{Ga} /{ }^{111} \mathrm{In}-\mathrm{NOTA}-\mathrm{P} 2-\mathrm{RM} 26\left(350 \mathrm{kBq}\right.$ of ${ }^{68} \mathrm{Ga}$ and $10 \mathrm{kBq}$ of ${ }^{111} \mathrm{In}, 100 \mu \mathrm{L}$ PBS$)$ intravenously. The mice were euthanized at 1,3 and $24 \mathrm{~h}$ p.i. and organ radioactivity content was measured and evaluated as described above. In order to test in vivo binding specificity, a group of animals was co-injected with $20 \mathrm{nmol}$ of unlabeled peptide. For animals in blocked group only blood, pancreas and tumors were collected at $1 \mathrm{~h}$ p.i.

Tumor bearing mice were injected with 45 pmol of ${ }^{111}$ In-NOTA-P2-RM26 (260 kBq) or ${ }^{68} \mathrm{Ga}-$ NOTA-P2-RM26 (300 kBq). ${ }^{111}$ In-NOTA-P2-RM26 injected animal was sacrificed 3 h p.i. and scanned by a clinical gamma camera (Siemens e.cam) equipped with a MEGP collimator. For ${ }^{68}$ Ga-NOTA-P2-RM26, images were acquired at 1 and $2 \mathrm{~h}$ p.i. using a micro-PET/CT (Gamma Medica Inc). PET and CT data were fused and analyzed in PMOD v3.13 (PMOD Technologies Ltd).

\section{Data analysis and statistics:}

Data were analyzed by unpaired two-tailed $t$-test using GraphPad Prism (version 4.00 for Windows GraphPad Software) to differentiate significant statistical difference $(p<0.05)$. For duallabel experiments paired test wased. 


\section{Results}

\section{Peptide synthesis:}

NOTA-P2-RM26 was synthesized and purified as described in Supplemental materials. Lyophilization of adequate fractions after HPLC purification afforded $9.2 \mathrm{mg}$ of the purified product, corresponding to a total yield of $44 \%$ (based on the initial resin loading). HPLC/MS analysis of the final product using Kinetex $2.6 \mu \mathrm{m} \mathrm{C18}(50 \times 3.0 \mathrm{~mm})$ column and $2.5 \mathrm{~min}, 5-60 \%$ acetonitrile/water $(0.05 \%$ formic acid) gradient gave $\mathrm{M} / \mathrm{Z}$ values in accordance with those expected (1544.88). The purity, as determined from $280 \mathrm{~nm}$ trace, was $96.7 \%$ (Figure S1).

\section{Radiolabeling and in vitro stability testing:}

Almost quantitative radioactivity incorporation in the labeling of both ${ }^{111}$ In-NOTA-P2-RM26 and ${ }^{68}$ Ga-NOTA-P2-RM26 (98.6 $\pm 0.6 \%$ for both) allowed the use of the tracers without further purification (Figure S2). The maximum specific radioactivity of $6 \mathrm{GBq} / \mu \mathrm{mol}$ and $20 \mathrm{GBq} / \mu \mathrm{mol}$ was obtained for ${ }^{111}$ In-NOTA-P2-RM26 and ${ }^{68}$ Ga-NOTA-P2-RM26, respectively.

After $1 \mathrm{~h}$ incubation at RT with 500-fold molar excess of EDTA, $90.5 \%$ of the radioactivity for

${ }^{111}$ In-NOTA-P2-RM26 and more than $97 \%$ of the radioactivity for ${ }^{68}$ Ga-NOTA-P2-RM26 was still associated with peptide. Furthermore, SDS-PAGE demonstrated high stability for ${ }^{68} \mathrm{Ga}-$ NOTA-P2-RM26 and ${ }^{111}$ In-NOTA-P2-RM26 (Figure S3). No release of radioactivity was detected for both of the compounds after $1 \mathrm{~h}$ incubation in mouse serum at $37^{\circ} \mathrm{C}$.

\section{In vitro studies:}


In vitro binding specificity tests demonstrated that the binding of the ${ }^{111} \mathrm{In}$ - and ${ }^{68}$ Ga-NOTA-P2RM26 to the PC-3 cells is receptor mediated. Pre-saturation of the cells with non-labeled NOTAP2-RM26 decreased the cell binding of the radiolabeled compounds significantly (Figure 1).

Binding of ${ }^{111}$ In-NOTA-P2-RM26 to PC-3 cells was rapid and cell associated radioactivity reached plateau in $4 \mathrm{~h}$ when approximately $40 \%$ from added radioactivity was cell associated (Figure 2A). The internalization of the ${ }^{111}$ In-labeled conjugate was low. After $24 \mathrm{~h}$ incubation, contribution of the internalized radioactivity in the overall cell-bound radioactivity was only $33 \pm 3 \%$. To further assess the internalization properties of the tracer, an internalization rate for ${ }^{68}$ Ga-NOTA-P2-RM26, ${ }^{111}$ In-NOTA-P2-RM26 and agonistic ${ }^{125} \mathrm{I}-\mathrm{Tyr}^{4}$-BBN by PC-3 cells was compared. After 30 min incubation at $37^{\circ} \mathrm{C}$, almost $50 \%$ of the ${ }^{125}$ I-radioactivity was internalized by the cells while less than $8 \%$ of the ${ }^{68} \mathrm{Ga}$ - or ${ }^{111}$ In-radioactivity was internalized (Figure $2 \mathrm{~B}$ ).

The $\mathrm{IC}_{50}$ values of ${ }^{\text {nat }}$ In-NOTA-P2-RM26 and ${ }^{\text {nat }}$ Ga-NOTA-P2-RM26 determined in inhibition experiment on PC-3 cells were 1.2 $\pm 0.3 \mathrm{nM}$ and $0.9 \pm 0.2 \mathrm{nM}$, respectively, and more than 4-folds lower than that of the non-labeled-NOTA-P2-RM26 $(5 \pm 1 \mathrm{nM})$ indicating the improvement of the affinity of the conjugate upon loading with metal cations (Figure 3).

The number of binding sites for antagonistic ${ }^{111}$ In- or ${ }^{68}$ Ga-NOTA-P2-RM26 was $280000 \pm 14000$ receptors/cell $(0.51 \pm 0.04 \mathrm{nM})$ while it was $120000 \pm 5000$ receptors/cell $(0.106 \pm 0.007 \mathrm{nM})$ for agonistic ${ }^{125} \mathrm{I}-\mathrm{Tyr}^{4}-\mathrm{BBN}$. According to LigandTracer data, the calculated $\mathrm{K}_{\mathrm{D}}$ for ${ }^{111} \mathrm{In}$-NOTA-P2RM26 was $23 \pm 13$ pM (Figure S4).

\section{In vivo studies:}


The biodistribution study in NMRI mice was performed to determine the cross-reactivity with murine GRPRs in normal organs and assess blood and whole body clearance of the radioconjugates (Figure 4, Table S1). Both radiopeptides showed rapid blood clearance. Liver uptake of both conjugates was low, and low level of radioactivity was detected in the gastrointestinal tract. Low renal radioactivity reabsorption and rapid wash out from the kidneys were observed. Specific uptake was found in GRPR-positive organs (pancreas, stomach, small intestine and spleen). Radioactivity washout from receptor positive organs was also rapid, e.g. radioactivity concentration in pancreas decreased more than 4 -fold between 1 and $2 \mathrm{~h}$ p.i.

Data on the influence of injected peptide dose on biodistribution and tumor-to-organ ratios for ${ }^{111}$ In-NOTA-P2-RM26 are presented in Figure 5 and Table S2. The results of biodistribution studies in NMRI and tumor bearing mice were in good agreement with regard to high tracer uptake in normal receptor positive organs. No significant difference in tumor-to-organ ratios could be observed for most of the organs and tissues by peptide dose varied between 3.6 to 45 pmol (Figure 5B).

The biodistribution and tumor targeting of ${ }^{68} \mathrm{Ga} /{ }^{111}$ In-NOTA-P2-RM26 in PC-3 xenografted mice was studied in a dual-isotope study and the results are presented in Figure 6 and Table S3. Both radioconjugates were rapidly cleared from blood. Low kidney retention and low liver uptake were displayed for tracers in tumor bearing mice. In a good agreement with biodistribution in NMRI mice, high uptake was observed for receptor positive organs. The washout rate from target-expressing normal tissues was higher than from tumors, leading to increasing tumor-toorgan ratios over time. High uptake and long retention of the radioconjugates was observed in the tumors. The uptake in the pancreas (GRPR expressing tissue in rodents) and the tumors was specific, as it was shown in in vivo saturation experiment. The pancreas uptake decreased more 
than 34-fold for ${ }^{111} \mathrm{In}$ - and 21 -fold for ${ }^{68} \mathrm{Ga}$-labeled conjugates in the animals co-injected with an excess of non-labeled peptide. The tumor radioactivity reduced from $5.97 \pm 0.27 \%$ ID/g to $0.50 \pm$ $0.27 \% \mathrm{ID} / \mathrm{g}$ for ${ }^{111} \mathrm{In}-\mathrm{NOTA}-\mathrm{P} 2-\mathrm{RM} 26$ and from $8.10 \pm 0.39 \% \mathrm{ID} / \mathrm{g}$ to $0.37 \pm 0.05 \% \mathrm{ID} / \mathrm{g}$ for ${ }^{68}$ Ga-NOTA-P2-RM26 after in vivo receptor saturation, which is an indication of specific GRPRmediated uptake.

The coronal gamma camera scan 3 h p.i. of ${ }^{111}$ In-NOTA-P2-RM26 is presented in Figure 7A. The tumor was clearly visualized. The abdominal receptor-positive organs and kidneys could also be seen on the gamma-camera image. MicroPET/CT images (Figure 7B and C) were obtained 1 and 2 h p.i. of ${ }^{68}$ Ga-NOTA-P2-RM26. Due to predominant renal excretion of the radioconjugate, high kidney uptake and urinary bladder accumulation were observed at $1 \mathrm{~h}$ p.i. Besides, a pancreatic uptake was visualized. Rapid washout of the tracer from normal organs including kidneys resulted in a microPET/CT image with absolutely dominant radioactivity accumulation in tumor 2 h p.i. 


\section{Discussion}

An accurate staging is crucial for selection of PC treatment. Sensitivity of the existing screening modalities is not high enough to confirm the presence and extent of disseminated cancer. This is especially important for visualization of the soft tissue metastases. In many cases this leads to understaging and overtreatment of PC patients. Overexpression of the GRPRs in human PC suggests that this receptor can be used for visualization and as therapeutic molecular target for PC patients, especially for soft tissue metastases targeting. ${ }^{5}$ Progression of PC leads to the transition of the androgen-responsive tumor growth toward hormone-refractory prostate cancer (HRPC). It has been reported that prostate tumors present different expression level of GRPRs in different stages of tumor progression. Overexpression of the GRPR was found for early stage, and in androgen-dependent prostate tumors, whereas low receptor-mediated binding of the radiolabeledbombesin analogs was observed for androgen-independent PC-xenografts. ${ }^{21}$ These results propose that GRPRs may be favorable targets for imaging and treatment of early stage PC tumors.

We have synthesized the NOTA-conjugated bombesin antagonist (D-Phe-Gln-Trp-Ala-Val-GlyHis-Sta-Leu-NH 2 ). Polyethylene glycol $\mathrm{PEG}_{2}$ was used as a linker conjugating NOTA chelator to the peptide. Adding to the overall hydrophilicity, PEG provides favorable pharmacokinetic properties for the peptide that manifested with low liver radioactivity uptake and rapid radioactivity excretion from normal GRPR organs. In further studies, the NOTA chelator will be suitable for labeling with many PET radionuclides such as metals ${ }^{68} \mathrm{Ga},{ }^{64} \mathrm{Cu},{ }^{55} \mathrm{Co}$, as well as for ${ }^{18} \mathrm{~F}-\mathrm{AlF}_{3}$. 
The peptide was stably radiolabeled with ${ }^{111} \mathrm{In}$ and ${ }^{68} \mathrm{Ga}$ with high labeling yields and specific radioactivities that permit the use of radiolabeled conjugates in in vitro and in vivo experiments without further purification.

A slow internalization rate into the PC-3 cells was observed for ${ }^{111}$ In-NOTA-P2-RM26 in the cellular processing experiment followed up to $24 \mathrm{~h}$. Internalization of ${ }^{68}$ Ga-NOTA-P2-RM26 or ${ }^{111}$ In-NOTA-P2-RM26 was 6-fold lower in comparison with internalization of agonistic analog ${ }^{125} \mathrm{I}_{-T y r}{ }^{4}-\mathrm{BBN}$ (Fig.2B), which was an indication of the preserved antagonistic function of RM26 after modification. $^{14}$

In order to compare binding properties of the new peptide loaded with indium or gallium and determine the influence of labeling on the binding affinity of the peptide, we performed a competitive binding assay using ${ }^{125} \mathrm{I}_{-} \mathrm{Tyr}^{4}-\mathrm{BBN}$ as displacement radioligand. The $\mathrm{IC}_{50}$ values for analogs loaded with metals were somewhat lower than non-labeled one. It has been demonstrated earlier that positively charged at the $\mathrm{N}$-terminus bombesin agonists exhibit higher affinities to the GRP receptors, while a negative charge decreases the affinity. ${ }^{12,22}$ The overall charge of a complex of dianionic NOTA with indium or gallium is +1 . This positive charge can explain the more than 4-fold lower $\mathrm{IC}_{50}$ values for metal loaded analogs compared with non-loaded peptide in our study.

The affinity $\left(\mathrm{K}_{\mathrm{D}}\right)$ in low picomolar range $(23 \pm 13 \mathrm{pM})$ was found for the ${ }^{111}$ In-NOTA-P2-RM26, and twice more binding sites on the human PC-derived PC-3 cells were recognized by antagonist peptide in comparison with ${ }^{125}$ I-labeled universal agonistic analog. These data was in a good agreement with the findings of other researchers. ${ }^{14,23}$ 
The biodistribution of ${ }^{111} \mathrm{In}$ - and ${ }^{68}$ Ga-labeled peptides in normal mice demonstrated specific uptake of the compounds in receptor-positive organs in the abdominal area (e.g. pancreas, stomach, small intestine and spleen). The blocking effect with the non-labeled peptide in receptor-expressing organs suggests that this peptide analog has cross-reactivity to murine GRPR. Kidneys were predominant excretion organ because radioactivity uptake both in liver and in gastrointestinal tract (with content) was low. However, kidney radioactivity uptake was as low as $5 \pm 2 \% \mathrm{ID} / \mathrm{g}$ already $1 \mathrm{~h}$ p.i. that indicates low degree of reabsorption and rapid excretion.

The influence of the administrated peptide dose on biodistribution and tumor targeting in PC-3 xenografted mice was studied and no significant differences in tumor-to-organ ratios were found within dose range between 3.6 and 45 pmol per mouse. This finding together with absence of agonistic action of NOTA-P2-RM26 suggests a wide window for peptide dose administration.

The biodistribution of ${ }^{111}$ In-NOTA-P2-RM26 was similar to that of the ${ }^{68}$ Ga-labeled peptide. Both tracers showed rapid blood and whole body clearance along with specific uptake in tumors and receptor expressing organs. The ${ }^{111}$ In-labeled conjugate showed somewhat more rapid blood clearance, but significantly higher tumor uptake for ${ }^{68} \mathrm{Ga}$-labeled analog resulted in higher tumorto-organ ratios in comparison with the ${ }^{111}$ In-labeled tracer.

The fast washout of the tracers from GRPR-positive organs together with high retention of the radiolabeled peptide in tumor xenografts suggest that this antagonistic NOTA-P2-RM26 has high potential for visualization of GRPR-positive tumors, even at very early time points. This permits the use of a short-lived generator-produced radioisotope ${ }^{68} \mathrm{Ga}$. This pharmacokinetic behavior (stable tumor uptake and rapid radioactivity release from GRPR-positive organs) may be due to affinity to murine GRPR and/or differences in target expression density between tumor and 
receptor-positive organs. Despite a high interspecies homology (>90\%) between murine and human GRPRs, ${ }^{24}$ different binding affinity of bombesin analogs have been demonstrated to bombesin receptors in different species. ${ }^{25}$ Even small differences in affinity can affect the retention of the radioactivity in receptor positive tissues with mouse GRPR expression and xenografts with human GRPRs. Target expression level also has direct effect on ligand retention. It has been shown that retention of the HER2-binding affibody molecules with $\mathrm{K}_{\mathrm{D}}$ values of 116.7 \pm 0.1 and $157 \pm 4 \mathrm{pM}$ in xenografts with high receptor expression (SKOV-3) was longer than retention of the same high affinity ligand in low HER2-expressing xenografts (LS174T). ${ }^{26}$ So the long tumor retention of the radiolabeled bombesin analog may also be the result of higher GRPRexpression on PC-3 cells or combination of both these factors.

The high potential of the radiolabeled conjugates for visualization of GRPR-positive tumors was confirmed by gamma-camera and microPET/CT images. Our biodistribution studies suggest that a suitable time point for image acquisition should be 2-3 h p.i. when the high tumor-to-receptor positive organs and tumor-to-kidney ratios were obtained. The best image contrast, which is the most important parameter for informative images in clinics, was obtained for ${ }^{68} \mathrm{Ga}$-labeled analog 2 h p.i.

In comparison with biodistribution data reported for ${ }^{111} \mathrm{In}-\mathrm{RM} 1$ and ${ }^{68} \mathrm{Ga}-\mathrm{RM} 2$ (1 h p.i.), ${ }^{111} \mathrm{In} /{ }^{68} \mathrm{Ga}-\mathrm{NOTA}-\mathrm{P} 2-\mathrm{RM} 26$ variants have (i) the same blood clearance rates, (ii) slightly higher liver uptake combined with lower radioactivity accumulation in the kidneys and (iii) up to 5-fold lower pancreas uptake. It has previously been reported that positively charged peptides are preferably taken up by liver. ${ }^{27} \mathrm{~N}$-terminus positive charge of ${ }^{68} \mathrm{Ga} /{ }^{111}$ In-NOTA-P2-RM26 might result in elevated liver accumulation and that the kidney uptake was decreased. It is also known that uptake of radiolabeled bombesin analogs in the pancreas descends as the lipophilicity of the 
conjugated decreases. ${ }^{28}$ Lower pancreas uptake for ${ }^{68}$ Ga-NOTA-P2-RM26 resulted in enhanced contrast in the abdominal area, which has the highest likelihood of visualization of distant soft tissue metastases in comparison with ${ }^{68} \mathrm{Ga}$-labeled RM1 and RM2. Liver metastases are not infrequent, but since they appear to be a fairly late event for PC patients we are not aiming for imaging at that late-stage. ${ }^{29}$ An important finding from this study is that small modifications in the chelation part and/or in the linker conjugating chelator to the peptide can dramatically alter the targeting properties of the peptide.

\section{Conclusion:}

We have developed a peptide-based imaging agent for visualization of GRPR expressing tumors using PET and SPECT. This tracer has capacity for further clinical consideration to overcome deficiencies of widely used metabolic PET tracers like $\left[{ }^{18} \mathrm{~F}\right]$-FDG, $\left[{ }^{11} \mathrm{C}\right]$-choline or $\left[{ }^{11} \mathrm{C}\right]$-acetate for imaging of prostate cancer.

\section{ACKNOWLEDGEMENTS:}

This research was financially supported by Swedish Cancer Society (Cancerfonden) and the Swedish Research Council (Vetenskapsrådet).

\section{ABREVIATIONS}

BN - bombesin; DOTA - 1,4,7,10-tetraazacyclododecane-1,4,7,10-tetraacetic acid; GRPR gastrin releasing peptide receptors; ITLC - instant thin-layer chromatography; NOTA - 1,4,7triazacyclononane-1,4,7-triacetic acid; NOTA-P2-RM26 - NOTA-PEG 2 -[D$\mathrm{Phe}^{6}, \mathrm{Sta}^{13}, \mathrm{Leu}^{14}$ ]bombesin[6-14]; PEG - polyethylene glycol; PC - prostate cancer; PET - 
positron emission tomography; p.i. - post injection; RT - room temperature; SDS-PAGE sodium dodecyl sulfate polyacrylamide gel electrophoresis; SPECT - single photon emission computed tomography; \%ID/g - percentage of injected dose per gram of tissue.

\section{CONFLICT OF INTEREST}

The authors declare no competing financial interest.

\section{SUPPORTING INFORMATION AVAILABLE:}

1. Peptide synthesis description.

2. Table S1. Biodistribution of ${ }^{68}$ Ga-NOTA-P2-RM26 and ${ }^{111}$ In-NOTA-P2-RM26 (total injected mass 23 pmol) after injection in male NMRI mice.

3. Table $\mathrm{S} 2$. Dose escalation study in BALB/c nu/nu male mice bearing PC-3 xenografts at 2 h p.i. of 111 In-NOTA-P2-RM26.

4. Table S3. Biodistribution of ${ }^{68} \mathrm{Ga}-\mathrm{NOTA}-\mathrm{P} 2-\mathrm{RM} 26$ and ${ }^{111}$ In-NOTA-P2-RM26 (total injected mass $45 \mathrm{pmol}$ ) after injection in male $\mathrm{BALB} / \mathrm{c} \mathrm{nu} / \mathrm{nu}$ mice bearing $\mathrm{PC}-3$ xenografts.

5. Figure S1. Results of HPLC and LC-MS analyses of NOTA-P2-RM26.

6. Figure S2. Results of HPLC analyses of ${ }^{68}$ Ga-NOTA-P2-RM26.

7. Figure S3. SDS-PAGE analysis of ${ }^{68}$ Ga-NOTA-P2-RM26 and ${ }^{111}$ In-NOTA-P2-RM26 after $1 \mathrm{~h}$ incubation with a 500-fold molar excess of EDTA at RT.

8. Figure S4. Real-time kinetics of peptide/cell surface receptor interactions in intact PC-3 cells for ${ }^{111}$ In-NOTA-P2-RM26. 


\section{References}

(1) Ciatto S, Zappa M, Bonardi R, Gervasi G. Prostate cancer screening: the problem of overdiagnosis and lessons to be learned from breast cancer screening. Eur $J$ Cancer. 2000 Jul;36(11):1347-50.

(2) de Visser M, van Weerden WM, de Ridder CM, Reneman S, Melis M, Krenning EP, de Jong M; Androgen-dependent expression of the gastrin-releasing peptide receptor in human prostate tumor xenografts. J Nucl Med. 2007;48(1):88-93.

(3) Perlmutter MA, Lepor H. Androgen Deprivation Therapy in the Treatment of Advanced Prostate Cancer. Rev Urol. 2007;9(suppl 1):S3-S8

(4) Even-Sapir E. Imaging of Malignant Bone Involvement by Morphologic, Scintigraphic, and Hybrid Modalities. J Nucl Med 2005;46:1356-1367.

(5) Jensen RT, Battey JF, Spindel ER, Benya RV. International Union of Pharmacology. LXVIII. Mammalian Bombesin Receptors: Nomenclature, distribution, pharmacology, signaling and functions in normal and disease states. Pharmacol Rev. 2008;60(1): 1-42.

(6) Minamino N, K Kangawa, H Matsuo; Neuromedin B: a novel bombesin-like peptide identified in porcine spinal cord. Biochem Biophys Res Commun. 1983 Jul 29:114(2): 541-548

(7) McDonald TJ, Nilsson G, Vagne M, Ghatei M, Bloom S R, Mutt V. A gastrin releasing peptide from the porcine nonantral gastric tissue; Gut, 1978, 19, 767-774

(8) Nock BA, Nikolopoulou A, Galanis A, Cordopatis P, Waser B, Reubi JC, Maina T. Potent bombesin-like peptides for GRP-receptor targeting of tumors with $99 \mathrm{mTc}$ : a preclinical study. J Med Chem. 2005;48(1):100-10.

(9) Zhang X, Cai W, Cao F, Schreibmann E, Wu Y, Wu JC, Xing L, Chen X. 18Flabeled bombesin analogs for targeting GRP receptor-expressing prostate cancer. $J$ Nucl Med. 2006;47(3):492-501.

(10) Dimitrakopoulou-Strauss A, Hohenberger P, Haberkorn U, Mäcke HR, Eisenhut M, Strauss LG. 68Ga-labeled bombesin studies in patients with gastrointestinal stromal tumors: comparison with 18F-FDG. J Nucl Med. 2007;48(8):1245-50.

(11) Van de Wiele C, Dumont F, Vanden Broecke R, Oosterlinck W, Cocquyt V, Serreyn R, Peers S, Thornback J, Slegers G, Dierckx RA. Technetium-99m RP527, a GRP analogue for visualisation of GRP receptor-expressing malignancies: a feasibility study. Eur J Nucl Med. 2000;27(11):1694-9.

(12) Abiraj K, Mansi R, Tamma ML, Fani M, Forrer F, Nicolas G, Cescato R, Reubi JC, Maecke HR. Bombesin antagonist-based radioligands for translational nuclear imaging of gastrin-releasing peptide receptor-positive tumors. $J$ Nucl $\mathrm{Med}$. 2011;52(12):1970-8.

(13) Llinares M, Devin C, Chaloin O, Azay J, Noel-Artis AM, Bernad N, Fehrentz JA, Martinez J. Syntheses and biological activities of potent bombesin receptor antagonists. J Pept Res. 1999;53(3):275-83.

(14) Mansi R, Wang X, Forrer F, Kneifel S, Tamma ML, Waser B, Cescato R, Reubi JC, Maecke HR. Evaluation of a 1,4,7,10-tetraazacyclododecane-1,4,7,10-tetraacetic acid-conjugated bombesin-based radioantagonist for the labeling with single-photon emission computed tomography, positron emission tomography, and therapeutic radionuclides. Clin Cancer Res. 2009;15(16):5240-9. 
(15) Mansi R, Wang X, Forrer F, Waser B, Cescato R, Graham K, Borkowski S, Reubi JC, Maecke HR. Development of a potent DOTA-conjugated bombesin antagonist for targeting GRPr-positive tumours. Eur J Nucl Med Mol Imaging.2011;38(1):97-107.

(16) Velikyan I, Maecke H, Langstrom B. Convenient preparation of 68Ga-based PETradiopharmaceuticals at room temperature. Bioconjug Chem. 2008, 19, 569-573

(17) Atherton E, Sheppard R. Fluorenylmethoxycarbonyl-polyamide solid phase peptide synthesis. General principles and development. Oxford:Oxford Information Press; 1989.

(18) Altai M, Varasteh Z, Andersson K, Eek A, Boerman O, Orlova A. In vivo and in vitro studies on renal uptake of radiolabeled affibody molecules for imaging of HER2 expression in tumors, accepted to Cancer Biotherapy \& Radiopharmaceuticals.

(19) Björke H, Andersson K. Automated, high-resolution cellular retention and uptake studies in vitro. Applied Radiation and Isotopes, 2006;64(8):901-905.

(20) Björke H, Andersson K. Measuring the affinity of a radioligand with its receptor using a rotating cell dish with in situ reference area. Applied Radiation and Isotopes, 2006;64(1):32-37.

(21) de Visser M, van Weerden WM, de Ridder CM, Reneman S, Melis M, Krenning EP, de Jong M; Androgen-dependent expression of the gastrin-releasing peptide receptor in human prostate tumor xenografts. J Nucl Med. 2007 Jan;48(1):88-93.

(22) Zhang H. Design, Synthesis, and Preclinical Evaluation of Radiolabeled Bombesin Analogues for the Diagnosis and Targeted Radiotherapy of Bombesinreceptor Expressing Tumors [PhD thesis]; Basel, Switzerland: Basel University, 2007; http://edoc.unibas.ch/586/1/DissB_7877.pdf

(23) Ginj M, Zhang H, Waser B, Cescato R, Wild D, Wang X, Erchegyi J, Rivier J, Mäcke HR, Jean Reubi C. Radiolabeled somatostatin receptor antagonists are preferable to agonists for in vivo peptide receptor targeting of tumors. Proc Natl Acad Sci U S A. 2006; 103(44): 16436-16441.

(24) Giladi E, Nagalla SR, Spindel ER. Molecular cloning and characterization of receptors for the mammalian bombesin-like peptides. J Mol Neurosci. 1993;4(1):4154.

(25) Maina T, Nock BA, Zhang H, Nikolopoulou A, Waser B, Reubi JC, Maecke HR. Species differences of bombesin analog interactions with GRP-R define the choice of animal models in the development of GRP-R-targeting drugs. $J$ Nucl Med. 2005;46(5):823-30.

(26) Tolmachev V, Tran TA, Rosik D, Sjöberg A, Abrahmsén L, Orlova A. Tumor Targeting Using Affibody Molecules: Interplay of Affinity, Target Expression Level, and Binding Site Composition. J Nucl Med. 2012 Jun;53(6):953-60

(27) Tran TA, Ekblad T, Orlova A, Sandström M, Feldwisch J, Wennborg A, Abrahmsén L, Tolmachev V, Eriksson Karlström A. Effects of lysine-containing mercaptoacetyl-based chelators on the biodistribution of $99 \mathrm{mTc}$-labeled anti-HER2 Affibody molecules. Bioconjug Chem. 2008 Dec;19(12):2568-76.

(28) Timothy J. Hoffman, Hariprasad Gali, C. Jeffrey Smith, Gary L. Sieckman, Donald L. Hayes, Nellie K. Owen, and Wynn A. Volkert. Novel Series of 111InLabeled Bombesin Analogs as Potential Radiopharmaceuticals for Specific Targeting of Gastrin-Releasing Peptide Receptors Expressed on Human Prostate Cancer Cells. $J$ Nucl Med. 2003;44:823-831. 
(29) Pouessel D, Gallet B, Bibeau F, Avancès C, Iborra F, Sénesse P, Culine S. Liver metastases in prostate carcinoma: clinical characteristics and outcome. BJU Int. 2007 Apr;99(4):807-11. 


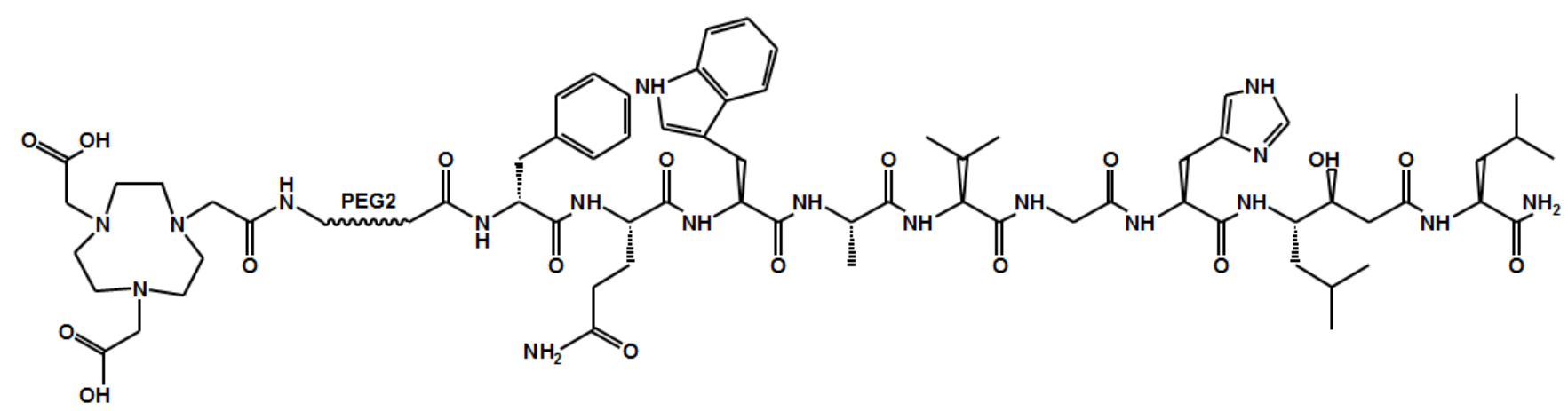

Chart Structure formula of NOTA-PEG $2_{2}\left[\mathrm{D}-\mathrm{Phe}^{6}, \mathrm{Sta}^{13}{ }^{13} \mathrm{Leu}^{14}\right]$ bombesin[6-14] (NOTA-P2RM26). 

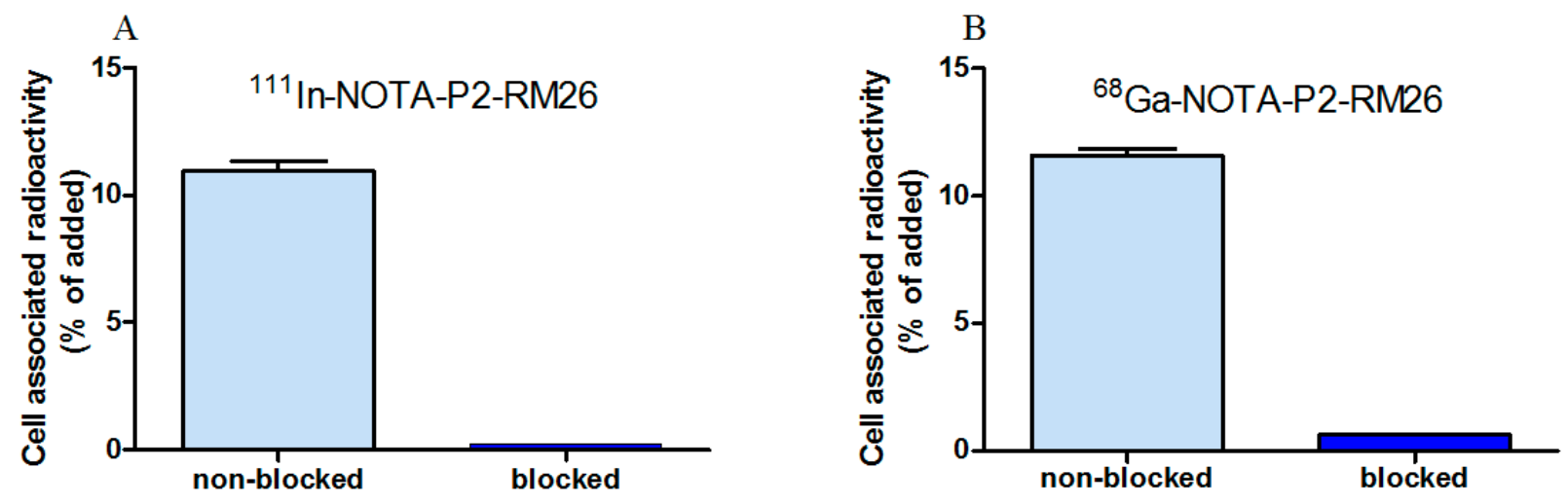

Figure 1. In vitro specificity test for ${ }^{111} \mathrm{In}$ - and ${ }^{68}$ Ga-NOTA-P2-RM26 on PC3 cells. Radiolabeled conjugates were added to culture cells at $1 \mathrm{nM}$ concentration. One set of culture dishes in each experiment was pretreated with 100-fold molar excess of non-labeled NOTA-P2-RM26 before incubation with labeled conjugate. Data are presented as mean values of three dishes $\pm \mathrm{SD}$. 

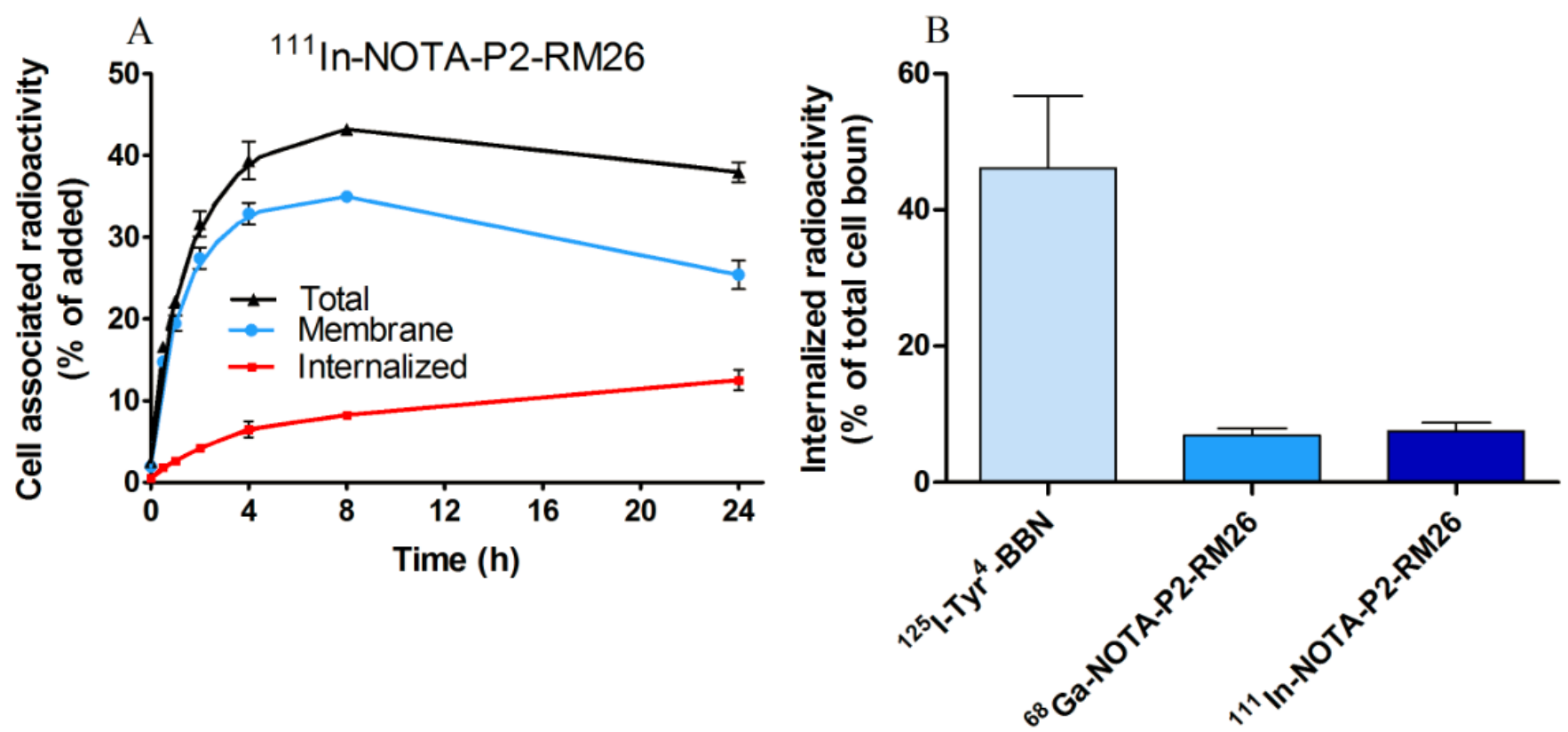

Figure 2. (A) Cellular processing of ${ }^{111}$ In-NOTA-P2-RM26 by PC-3 cells during continuous incubation with $1 \mathrm{nM}$ of ${ }^{111}$ In-NOTA-P2-RM26. (B) Internalization assay performed on PC-3 cells using ${ }^{125} \mathrm{I}-\mathrm{Tyr}^{4}$-BBN (agonist), ${ }^{68}$ Ga-NOTA-P2-RM26 and ${ }^{111}$ In-NOTA-P2-RM26 (antagonist). Data are presented as mean values of three dishes \pm SD. 


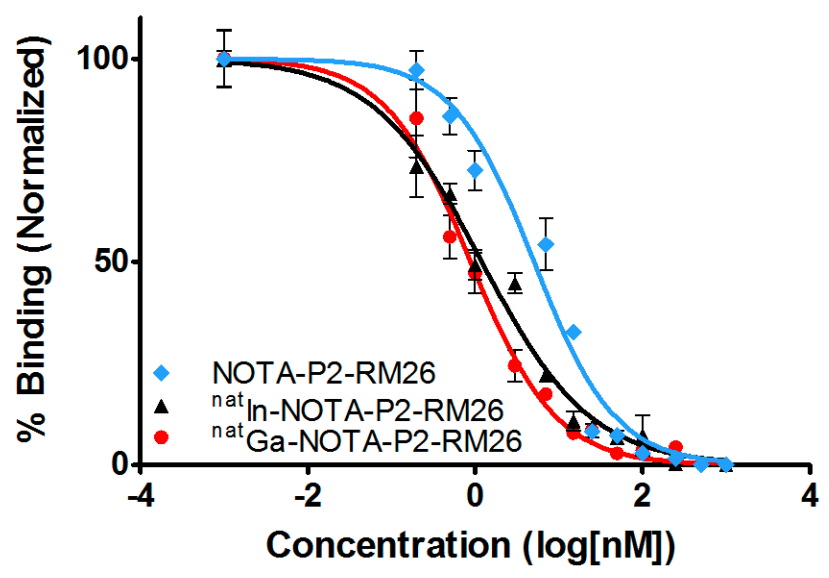

Figure 3. Inhibition of ${ }^{125} \mathrm{I}_{-\mathrm{Tyr}}{ }^{4}-\mathrm{BBN}$ binding to PC3 cells with ${ }^{\text {nat }}$ Ga-NOTA-P2-RM26, ${ }^{\text {nat }}$ InNOTA-P2-RM26, and non-labeled NOTA-P2-RM26. Data are mean values from 3 dishes \pm SD. 

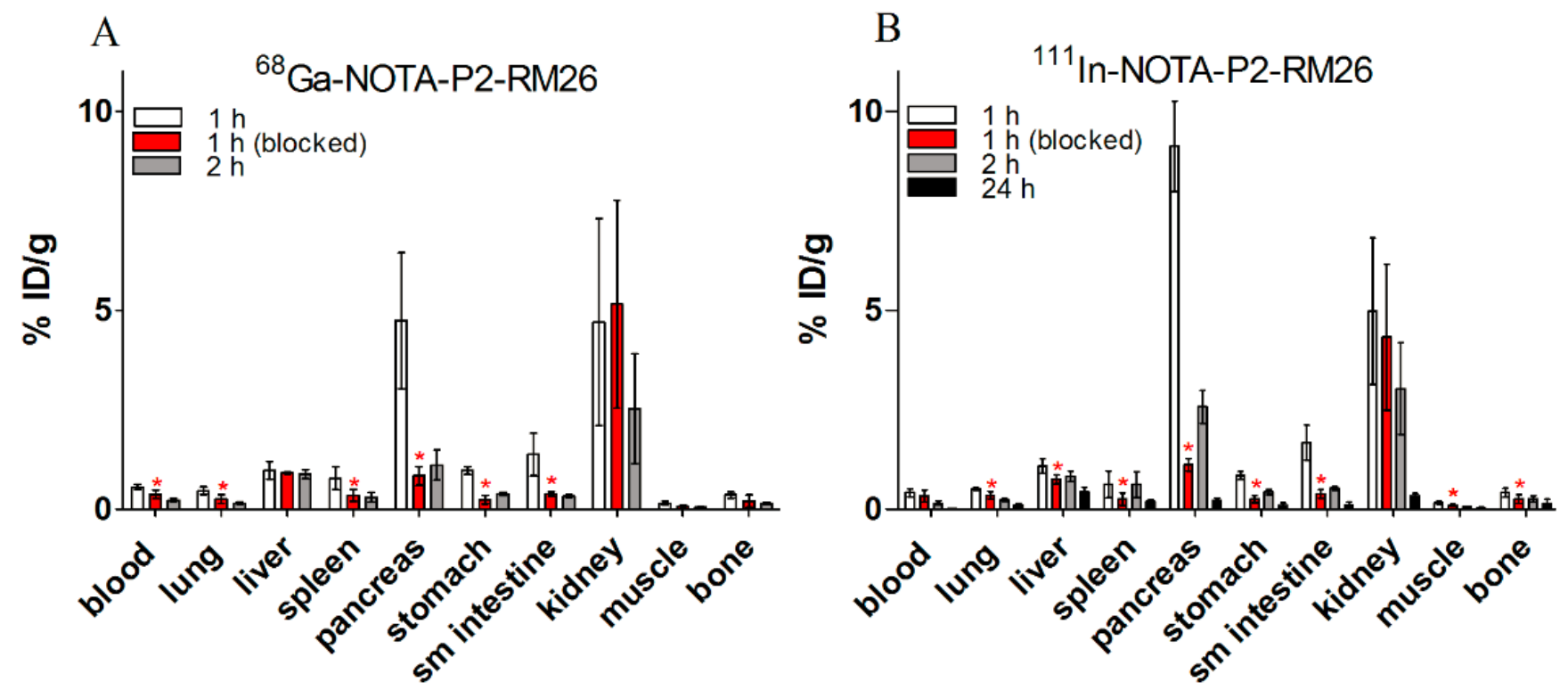

Figure 4. (A) Biodistribution of ${ }^{68}$ Ga-NOTA-P2-RM26 and (B) ${ }^{111}$ In-NOTA-P2-RM26 in male NMRI mice at different time points in a dual-isotope study (total injected mass 23 pmol). Data are presented as mean percentage of injected dose per gram of tissue (\%ID/g $\pm \mathrm{SD}, \mathrm{n}=4)$. Red stars - The difference between blocked and non-blocked animals was significant $(p<0.05)$. 

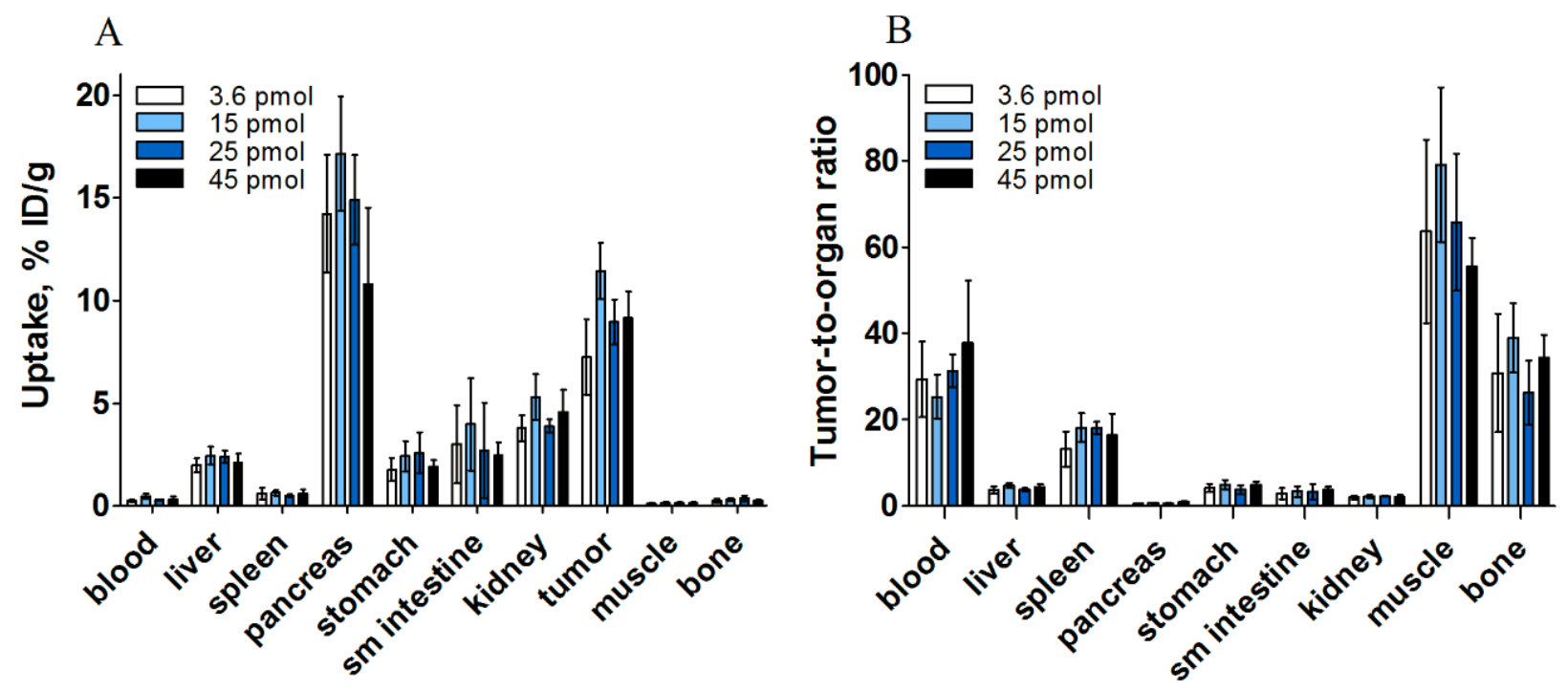

Figure 5. Dose escalation study in male BALB/c nu/nu mice bearing PC-3 xenografts of ${ }^{111}$ InNOTA-P2-RM26. (A) Biodistribution $2 \mathrm{~h}$ after injection and (B) tumor-to-organ at this time point. Data are presented as mean percentage of injected dose per gram of tissue $(\% \mathrm{ID} / \mathrm{g}) \pm \mathrm{SD}$ $(n=4)$. 

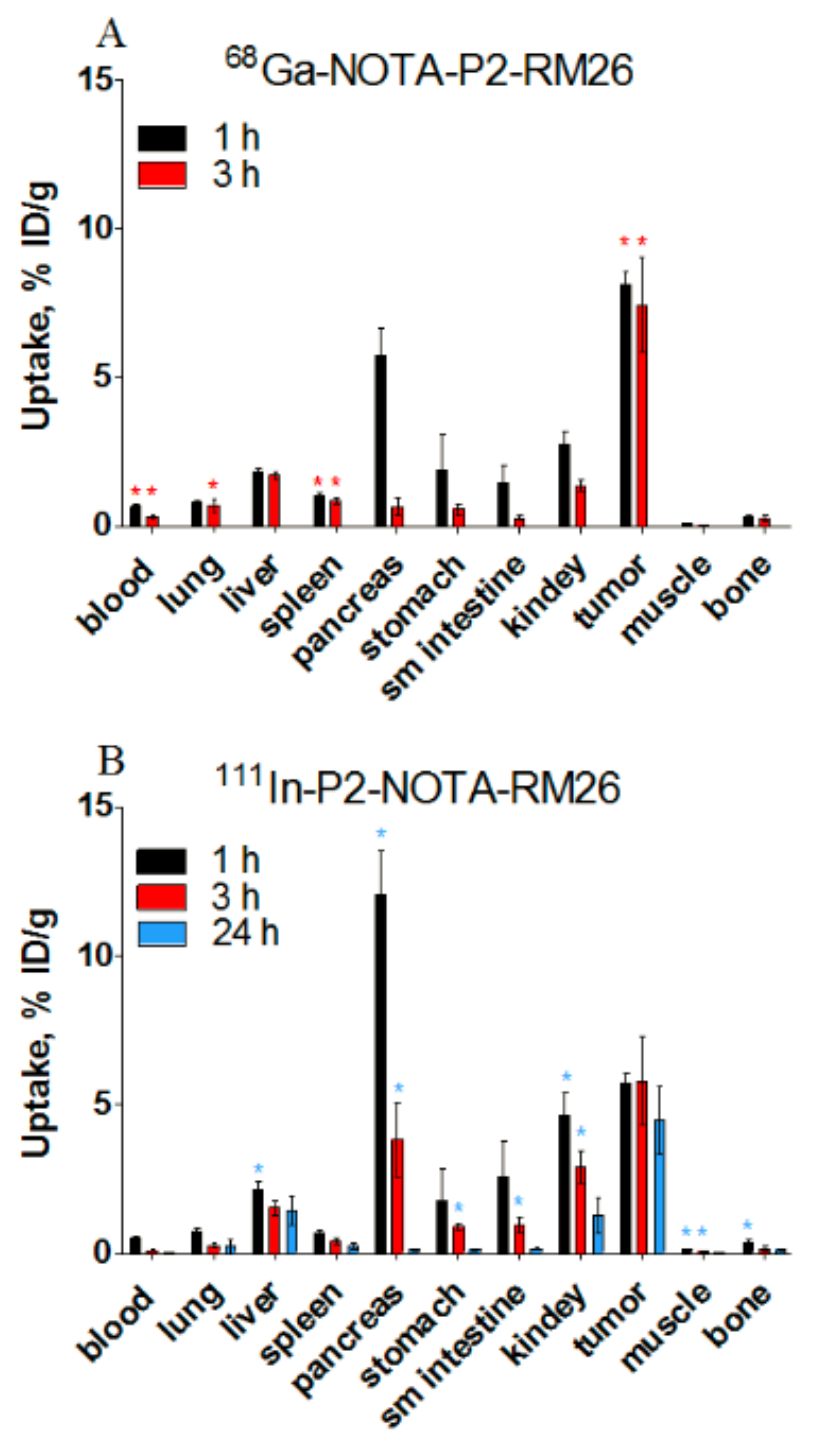

Figure 6. Biodistribution of ${ }^{68}$ Ga-NOTA-P2-RM26 (A) and ${ }^{111}$ In-NOTA-P2-RM26 (B) in male $\mathrm{BALB} / \mathrm{c}$ nu/nu mice bearing PC-3 xenografts at different time points in a dual-isotope study (total injected mass $45 \mathrm{pmol}$ ). Data are presented as mean percentage of injected dose per gram of tissue (\%ID/g $\pm \mathrm{SD}, \mathrm{n}=4)$. Red stars $-{ }^{68} \mathrm{Ga}-\mathrm{NOTA}-\mathrm{P} 2-\mathrm{RM} 26$ uptake is higher than ${ }^{111} \mathrm{In}-\mathrm{NOTA}-$ P2-RM26 significantly $(p<0.05)$ for the same time point. Blue stars - ${ }^{111}$ In-NOTA-P2-RM26 uptake is higher than ${ }^{68} \mathrm{Ga}-\mathrm{NOTA}-\mathrm{P} 2-\mathrm{RM} 26$ significantly for the same time point. 


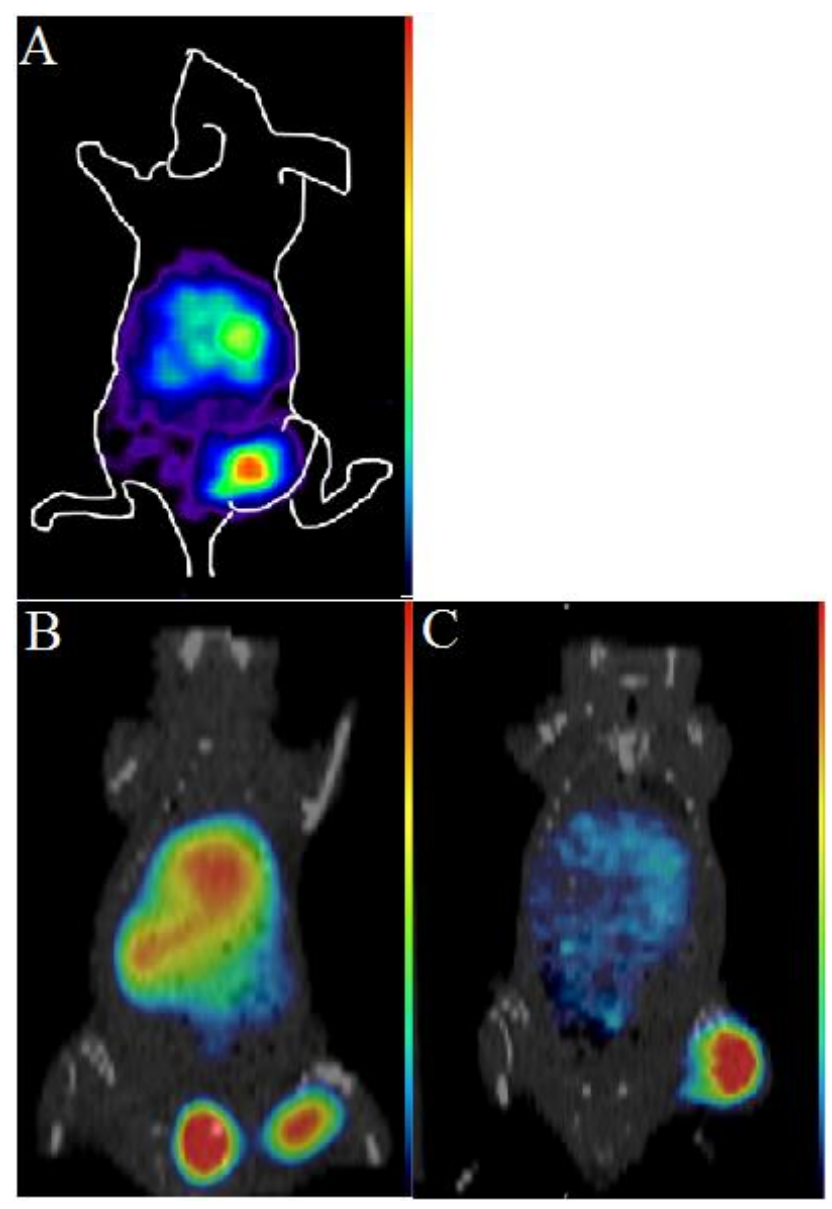

Figure 7. Imaging of GRPR expression in PC-3 xenografts in BALB/c nu/nu male mice. The animal for gamma camera imaging (A) was injected with 45 pmol of ${ }^{111}$ In-NOTA-P2-RM26 (260 $\mathrm{kBq}$ ) and euthanized $3 \mathrm{~h}$ p.i. Micro-PET/CT images were acquired at $1 \mathrm{~h}(\mathrm{~B})$ and $2 \mathrm{~h}(\mathrm{C})$ p.i. of 45 pmol of ${ }^{68} \mathrm{Ga}-\mathrm{NOTA}-\mathrm{P} 2-\mathrm{RM} 26(300 \mathrm{kBq})$. 


\section{SUPPORTING INFORMATION for}

\section{Synthesis and characterization of a high affinity NOTA-conjugated bombesin antagonist for GRPR-targeted tumor imaging}

Z. Varasteh, I. Velikyan, G. Lindeberg, J. Sörensen, M. Larhed, M. Sandström, R.K. Selvaraju, J. Malmberg, V. Tolmachev, A. Orlova

Peptide synthesis:

For NOTA-PEG ${ }_{2}-\left[\mathrm{D}-\mathrm{Phe}^{6}, \mathrm{Sta}^{13}{ }^{13} \mathrm{Leu}^{14}\right]$ bombesin[6-14], NOTA-P2-RM26 (Figure1) production, partially protected $\left[\mathrm{D}-\mathrm{Phe}^{6}, \mathrm{Sta}^{13}, \mathrm{Leu}^{14}\right.$ ]bombesin[6-14] resin was synthesized on an $80 \mu \mathrm{M}$ scale by manual solid-phase peptide synthesis (SPPS) in a $2 \mathrm{~mL}$ disposable syringe equipped with a porous polyethylene filter using standard Fmoc/t-Bu conditions. The starting resin was Rink amide MBHA polymer $(0.53 \mu \mathrm{mol} / \mathrm{g})$. For the Fmoc-amino acids the following side-chain protecting groups were used: His (Trt), Trp (Boc), Gln (Trt). Fmoc-statine was used without sidechain protection. Fmoc-amino acids (4 equiv.) were coupled for 2.5-5 h, using PyBOP (4 equiv.) in the presence of DIEA (6-8 equiv.) in DMF (0.65-0.75 mL). For Fmoc-statine the concentrations were reduced by a factor two and the reaction was allowed to proceed overnight. The Fmoc group was removed by treatment with $20 \%$ piperidine in DMF $(3 \times 1 \mathrm{~mL}, 1+10+10$ min). After completion of the sequence, the Fmoc group was removed, the resin washed extensively with DMF, DCM and $\mathrm{MeOH}$ and dried in vacuo to yield $303 \mathrm{mg}$ of the partially protected peptide resin. Part of the resin $(104 \mathrm{mg}$, ca. $27 \mu \mathrm{mol})$ was coupled overnight with Fmoc-O2Oc-OH (Fmoc- $\mathrm{PEG}_{2}-\mathrm{OH}, 5$ equiv.) using PyBOP and DIEA (5 and 7.5 equiv., respectively). The Fmoc group was then removed by treatment with piperidine as described above. After washing of the resin, NOTA $(t-\mathrm{Bu})_{2}-\mathrm{OH}$ (3 equiv.) was coupled overnight using PyBOP and DIEA (3 and 6 equiv., respectively). A final piperidine treatment $(10+10 \mathrm{~min})$ was 
performed in order to reverse possible acylation of the statine side chain. The resin was then washed extensively with DMF and DCM and dried in vacuo yielding $118 \mathrm{mg}$.

Two $\mathrm{ml}$ of TFA/thioanisol/water (92/6/2) was added to the resin $(110 \mathrm{mg})$ and the brownish suspension was rotated in a $3.5 \mathrm{~mL}$ centrifuge tube at room temperature for $1.5 \mathrm{~h}$. After centrifugation, triethylsilane ( $50 \mu \mathrm{L})$ was added (decoloration) and the resin was removed by filtration through a small plug of glass wool in a Pasteur pipette and rinsed with TFA ( $3 \times 300 \mu \mathrm{L})$. The filtrate was concentrated in a stream of nitrogen to almost $1 \mathrm{ml}$ and the product precipitated by addition of ether $(12 \mathrm{~mL})$. The precipitate was recovered by centrifugation, washed with ether $(4 \times 6 \mathrm{~mL})$ and dried in a stream of nitrogen and then in vacuo overnight to yield $46.3 \mathrm{mg}$ of the crude product.

Part of the material $(24.7 \mathrm{mg})$ was dissolved in $10 \%$ aq. $\mathrm{MeCN}(2 \mathrm{~mL})$ and purified twice on a Nucleodur HTech $5 \mu \mathrm{m}$ C18 column $(125 \times 21 \mathrm{~mm})$ using a $30-\mathrm{min} 15-55 \%$ MeCN- $\mathrm{H}_{2} \mathrm{O}(0.1 \%$ TFA) gradient. 
Table S1. Biodistribution of ${ }^{68}$ Ga-NOTA-P2-RM26 and ${ }^{111}$ In-NOTA-P2-RM26 (total injected mass 23 pmol) after injection in male NMRI mice. One group of animals was i.v. pre-injected 60 min before injection of radiolabelled conjugate with $20 \mathrm{nmol}$ of non-labeled NOTA-P2-RM26 (designated as blocked). Data are presented as mean percentage of injected dose per gram of tissue $(\% \mathrm{ID} / \mathrm{g} \pm \mathrm{SD}, \mathrm{n}=4)$. Data for gastrointestinal tract and carcass are presented as \%ID per whole sample.

\section{${ }^{68}$ Ga-NOTA-P2-RM26 $\quad \stackrel{111 \text { In-NOTA-P2-RM26 }}{ }$}

\begin{tabular}{|l|ccc|cccc}
\hline Organ and tissue & $1 \mathrm{~h}$ & $\begin{array}{c}1 \mathrm{~h} \\
\text { (blocked) }\end{array}$ & $2 \mathrm{~h}$ & $1 \mathrm{~h}$ & $\begin{array}{c}1 \mathrm{~h} \\
\text { (blocked) }\end{array}$ & $2 \mathrm{~h}$ & $24 \mathrm{~h}$ \\
\cline { 2 - 8 } Blood & $0.56 \pm 0.06^{a b}$ & $0.38 \pm 0.09$ & $0.24 \pm 0.04$ & $0.42 \pm 0.08^{d}$ & $0.3 \pm 0.1$ & $0.15 \pm 0.04$ & $0.01 \pm 0.01$ \\
Lung & $0.48 \pm 0.08^{a b}$ & $0.26 \pm 0.10$ & $0.15 \pm 0.02$ & $0.52 \pm 0.04^{c d}$ & $0.35 \pm 0.08$ & $0.23 \pm 0.03$ & $0.12 \pm 0.02$ \\
Liver & $1.0 \pm 0.2$ & $0.92 \pm 0.02$ & $0.89 \pm 0.10$ & $1.1 \pm 0.2^{c}$ & $0.75 \pm 0.10$ & $0.8 \pm 0.1$ & $0.4 \pm 0.1$ \\
Spleen & $0.8 \pm 0.2^{a b}$ & $0.4 \pm 0.1$ & $0.3 \pm 0.1$ & $0.6 \pm 0.3^{c}$ & $0.3 \pm 0.1$ & $0.6 \pm 0.3$ & $0.20 \pm 0.03$ \\
Pancreas & $5 \pm 1^{a b}$ & $0.9 \pm 0.2$ & $1.1 \pm 0.3$ & $9.1 \pm 0.8^{c d}$ & $1.1 \pm 0.1$ & $2.6 \pm 0.3$ & $0.2 \pm 0.2$ \\
Stomach & $0.98 \pm 0.08^{a b}$ & $0.25 \pm 0.10$ & $0.39 \pm 0.03$ & $0.85 \pm 0.09^{c d}$ & $0.26 \pm 0.08$ & $0.43 \pm 0.05$ & $0.1 \pm 0.1$ \\
Small intestine & $1.4 \pm 0.5^{a b}$ & $0.40 \pm 0.05$ & $0.34 \pm 0.03$ & $1.7 \pm 0.4^{c d}$ & $0.39 \pm 0.09$ & $0.53 \pm 0.04$ & $0.11 \pm 0.05$ \\
Kidney & $5 \pm 2$ & $5 \pm 2$ & $3 \pm 1$ & $5 \pm 2$ & $4 \pm 2$ & $3 \pm 1$ & $0.33 \pm 0.06$ \\
Muscle & $0.15 \pm 0.04^{b}$ & $0.08 \pm 0.02$ & $0.05 \pm 0.02$ & $0.17 \pm 0.03^{c d}$ & $0.10 \pm 0.03$ & $0.07 \pm 0.01$ & $0.03 \pm 0.02$ \\
Bone & $0.37 \pm 0.07^{b}$ & $0.2 \pm 0.1$ & $0.15 \pm 0.02$ & $0.42 \pm 0.10^{c d}$ & $0.26 \pm 0.09$ & $0.26 \pm 0.06$ & $0.13 \pm 0.11$ \\
GI tract & $3.3 \pm 0.5^{a b}$ & $1.07 \pm 0.10$ & $2.0 \pm 0.1$ & $4.2 \pm 0.6^{c d}$ & $0.90 \pm 0.06$ & $1.7 \pm 0.2$ & $0.38 \pm 0.15$ \\
Carcass & $5 \pm 1^{b}$ & $3.1 \pm 0.9$ & $1.9 \pm 0.5$ & $6 \pm 1^{c d}$ & $4 \pm 1$ & $2.5 \pm 0.4$ & $0.76 \pm 0.06$ \\
\hline
\end{tabular}

${ }^{a}$ Significant difference $(p<0.05)$ between $1 \mathrm{~h}$ and $1 \mathrm{~h}$ blocked for ${ }^{68}$ Ga-NOTA-P2-RM26. ${ }^{b}$ Significant difference between $1 \mathrm{~h}$ and $2 \mathrm{~h}$ for ${ }^{68} \mathrm{Ga}$-NOTA-P2-RM26. ${ }^{c}$ Significant difference between $1 \mathrm{~h}$ and $1 \mathrm{~h}$ blocked for ${ }^{111}$ In-NOTA-P2-RM26. ${ }^{d}$ Significant difference between $1 \mathrm{~h}$ and $2 \mathrm{~h}$ for ${ }^{111}$ In-NOTA-P2-RM26. 

Table S2. Dose escalation study in BALB/c nu/nu male mice bearing PC-3 xenografts at $2 \mathrm{~h}$ p.i. of ${ }^{111}$ In-NOTA-P2-RM26. The organ and tissue uptake values are expressed as an average percentage of injected dose per gram of tissue and standard deviation based on data from four mice $(\% \mathrm{ID} / \mathrm{g} \pm \mathrm{SD})$.

\begin{tabular}{|l|cccc|}
\hline Organ and tissue & $\mathbf{3 . 6} \mathbf{~ p m o l}$ & $\mathbf{1 5} \mathbf{~ p m o l}$ & $\mathbf{2 5} \mathbf{~ p m o l}$ & $\mathbf{4 5} \mathbf{~ p m o l}$ \\
\hline blood & $0.26 \pm 0.07$ & $0.5 \pm 0.1$ & $0.29 \pm 0.04$ & $0.3 \pm 0.2$ \\
lung & $0.52 \pm 0.08$ & $0.6 \pm 0.4$ & $0.8 \pm 0.4$ & $0.6 \pm 0.1$ \\
liver & $2.0 \pm 0.3$ & $2.4 \pm 0.4$ & $2.4 \pm 0.3$ & $2.1 \pm 0.4$ \\
spleen & $0.60 \pm 0.28$ & $0.6 \pm 0.1$ & $0.50 \pm 0.07$ & $0.6 \pm 0.2$ \\
pancreas & $14 \pm 3$ & $17 \pm 3^{c}$ & $15 \pm 2$ & $11 \pm 4$ \\
stomach & $1.8 \pm 0.6$ & $2.4 \pm 0.7$ & $3 \pm 1$ & $1.9 \pm 0.3$ \\
sm intestine & $3 \pm 2$ & $4 \pm 2$ & $3 \pm 2$ & $2.5 \pm 0.6$ \\
kidney & $3.8 \pm 0.6$ & $5 \pm 1$ & $3.9 \pm 0.3$ & $5 \pm 1$ \\
tumor & $7 \pm 2^{a}$ & $11 \pm 1^{b}$ & $9 \pm 1$ & $9 \pm 1$ \\
muscle & $0.12 \pm 0.03$ & $0.15 \pm 0.05$ & $0.14 \pm 0.04$ & $0.13 \pm 0.04$ \\
bone & $0.26 \pm 0.10$ & $0.30 \pm 0.08$ & $0.4 \pm 0.2$ & $0.27 \pm 0.06$ \\
GI tract & 6.4 & $6.4 \pm 0.8$ & $7 \pm 2$ & $5 \pm 1$ \\
carcass & $6 \pm 1$ & $11 \pm 3^{\mathrm{c}}$ & $8 \pm 3$ & $6.8 \pm 1.0$ \\
\hline Tumor to organ & $9 \pm 3$ & & & \\
blood & & $25 \pm 5$ & $31 \pm 4$ & $38 \pm 14$ \\
lung & $29 \pm 9$ & $30 \pm 25$ & $12 \pm 4$ & $16 \pm 3$ \\
liver & $14 \pm 3$ & $4.7 \pm 0.5$ & $3.8 \pm 0.3$ & $4.4 \pm 0.7$ \\
spleen & $3.7 \pm 0.8$ & $18 \pm 3$ & $18 \pm 1$ & $17 \pm 5$ \\
pancreas & $13 \pm 4$ & $0.68 \pm 0.09$ & $0.61 \pm 0.08$ & $0.9 \pm 0.2$ \\
stomach & $0.5 \pm 0.1$ & $5 \pm 1$ & $4 \pm 1$ & $4.9 \pm 0.8$ \\
sm intentine & $4.2 \pm 0.9$ & $3 \pm 2$ & $3 \pm 2$ & $3.8 \pm 0.7$ \\
kidney & $3 \pm 1$ & $2.2 \pm 0.4$ & $2.3 \pm 0.1$ & $2.1 \pm 0.5$ \\
muscle & $1.9 \pm 0.5$ & $79 \pm 18$ & $66 \pm 16$ & $80 \pm 50$ \\
bone & $64 \pm 21$ & $39 \pm 8$ & $26 \pm 7$ & $34 \pm 5$ \\
\hline
\end{tabular}

${ }^{*}$ Data for gastrointestinal tract and carcass are presented as \%ID per whole sample. ${ }^{a}$ Significant difference $(p<0.05)$ between 3.6 and 15 pmol. ${ }^{b}$ Significant difference between 15 and 25 pmol. ${ }^{c}$ Significant difference between 15 and 45 pmol. 
Table S3. Biodistribution of ${ }^{68}$ Ga-NOTA-P2-RM26 and ${ }^{111}$ In-NOTA-P2-RM26 (total injected mass 45 pmol) after injection in male BALB/c nu/nu male mice bearing PC-3 xenografts. One group of animals was i.v. co-injected with $20 \mathrm{nmol}$ of non-labelled NOTA-P2-RM26 (designated as blocked). Data are presented as mean percentage of injected dose per gram of tissue $(\% \mathrm{ID} / \mathrm{g} \pm \mathrm{SD}, \mathrm{n}=4)$.

${ }^{68}$ Ga-NOTA-P2-RM26 $\quad \quad$ In-NOTA-P2-RM26

\begin{tabular}{|l|ccc|cccc}
\hline Organ and tissue & $1 \mathrm{~h}$ & $\begin{array}{c}1 \mathrm{~h} \\
\text { (blocked) }\end{array}$ & $3 \mathrm{~h}$ & $1 \mathrm{~h}$ & $\begin{array}{c}1 \mathrm{~h} \\
\text { (blocked) }\end{array}$ & $3 \mathrm{~h}$ & $24 \mathrm{~h}$ \\
\hline Blood & $0.68 \pm 0.04^{b}$ & $0.13 \pm 0.04^{a}$ & $0.32 \pm 0.05^{c}$ & $0.55 \pm 0.05$ & $0.13 \pm 0.04^{a}$ & 0.100 .01 & $0.022 \pm 0.005$ \\
Lung & $0.78 \pm 0.07$ & & $0.7 \pm 0.2^{c}$ & $0.7 \pm 0.1$ & & $0.28 \pm 0.05$ & $0.2 \pm 0.2$ \\
Liver & $1.83 \pm 0.07$ & & $1.7 \pm 0.1$ & $2.1 \pm 0.2^{b}$ & & $1.5 \pm 0.2$ & $1.4 \pm 0.4$ \\
Spleen & $1.04 \pm 0.06^{b}$ & & $0.8 \pm 0.1^{c}$ & $0.68 \pm 0.08$ & & $0.41 \pm 0.07$ & $0.3 \pm 0.1$ \\
Pancreas & $5.7 \pm 0.8$ & $0.25 \pm 0.02^{a}$ & $0.6 \pm 0.2$ & $12 \pm 1^{b}$ & $0.26 \pm 0.02^{a}$ & $3.38 \pm 1.08^{c}$ & $0.11 \pm 0.03$ \\
Stomach & $1.89 \pm 1.04$ & & $0.5 \pm 0.1$ & $1.7 \pm 0.9$ & & $0.89 \pm 0.08^{c}$ & $0.12 \pm 0.03$ \\
Small intestine & $1.4 \pm 0.5$ & & $0.27 \pm 0.05$ & $2.57 \pm 1.04$ & & $0.9 \pm 0.2^{c}$ & $0.17 \pm 0.04$ \\
Kidney & $2.7 \pm 0.4$ & & $1.4 \pm 0.1$ & $4.6 \pm 0.6^{b}$ & & $2.9 \pm 0.4^{c}$ & $1.3 \pm 0.5$ \\
Tumor & $8.1 \pm 0.4^{b}$ & $0.3 \pm 0.1^{a}$ & $7.4 \pm 1.4^{c}$ & $5.7 \pm 0.2$ & $0.37 \pm 0.05^{a}$ & $5.8 \pm 1.3$ & $4.5 \pm 0.9$ \\
Muscle & $0.09 \pm 0.01$ & & $0.03 \pm 0.01$ & $0.163 \pm 0.005^{b}$ & & $0.063 \pm 0.005^{c}$ & $0.039 \pm 0.008$ \\
Bone & $0.28 \pm 0.05$ & & $0.25 \pm 0.07$ & $0.38 \pm 0.08^{b}$ & & $0.17 \pm 0.07$ & $0.12 \pm 0.04$ \\
\hline
\end{tabular}

${ }^{a}$ Significant difference $(p<0.05)$ between $1 \mathrm{~h}$ and $1 \mathrm{~h}$ blocked for both of the compounds. ${ }^{b}$ Significantly $(p<0.05)$ higher uptake in comparison with counterpart for $1 \mathrm{~h}$ p.i. ${ }^{c}$ Significantly $(p<0.05)$ higher uptake in comparison with counterpart for $3 \mathrm{~h}$ p.i. 

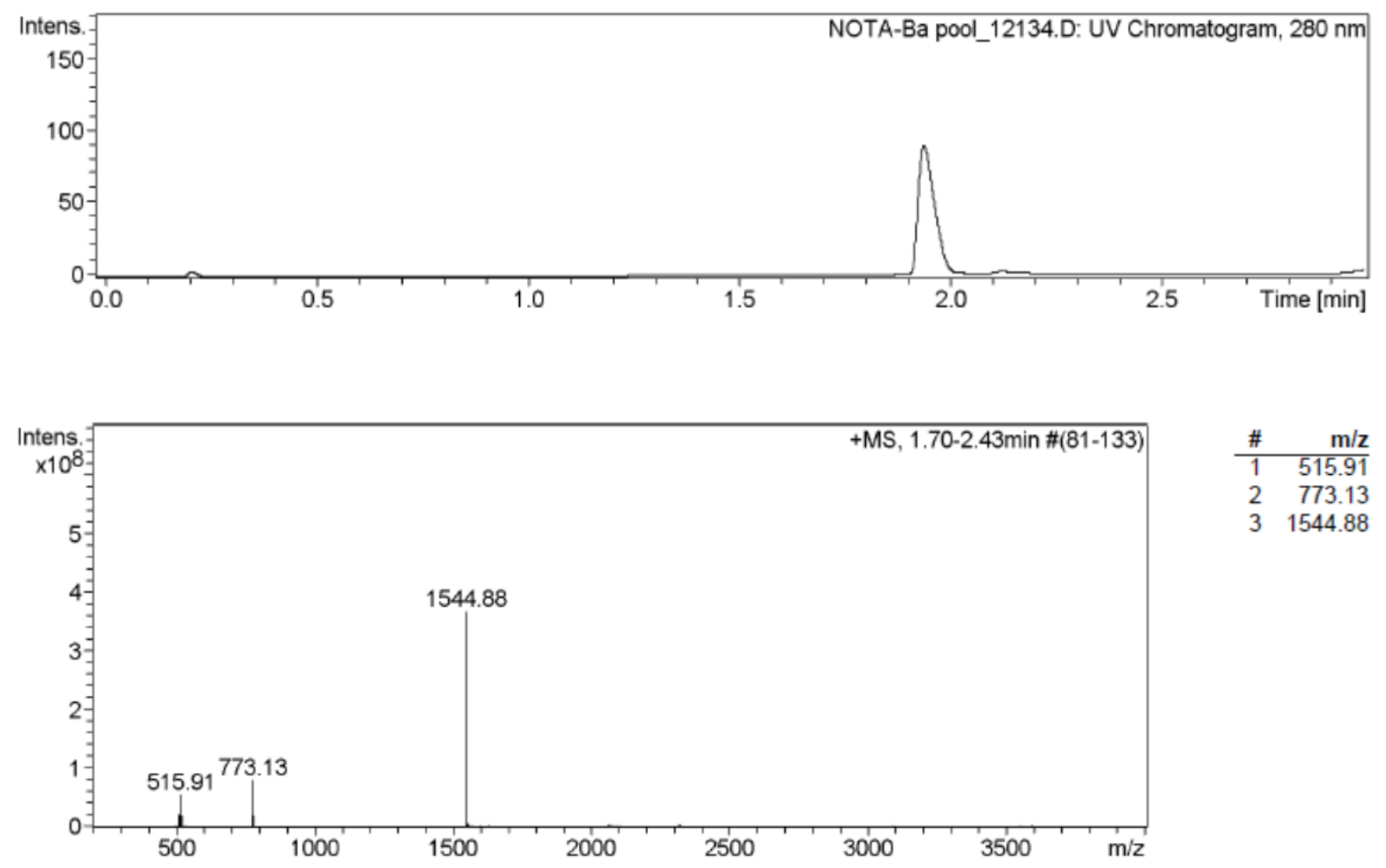

Figure S1. HPLC and LC-MS analyses of NOTA-P2-RM26. 

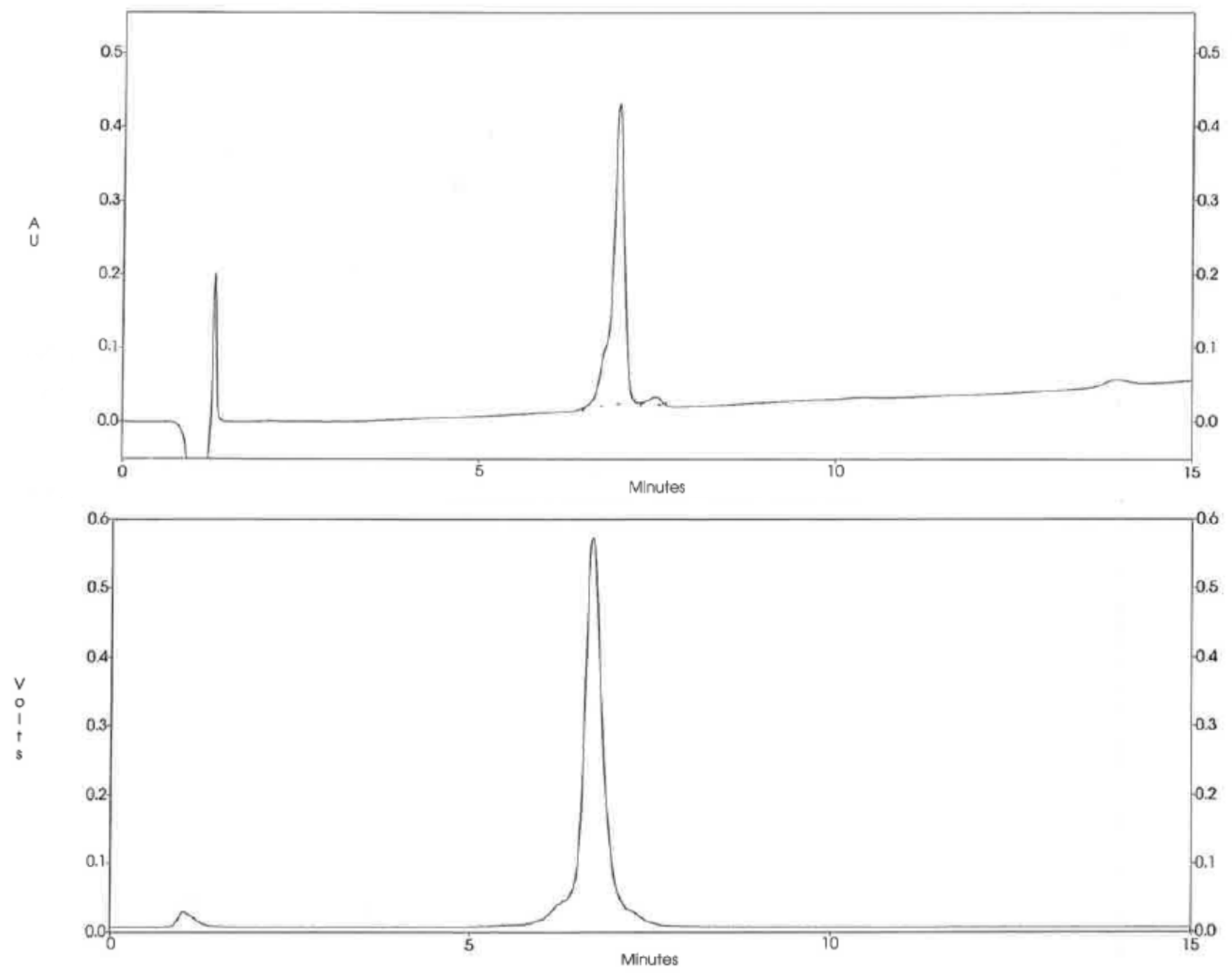

Figure S2. HPLC analyses of ${ }^{68}$ Ga-NOTA-P2-RM26. 

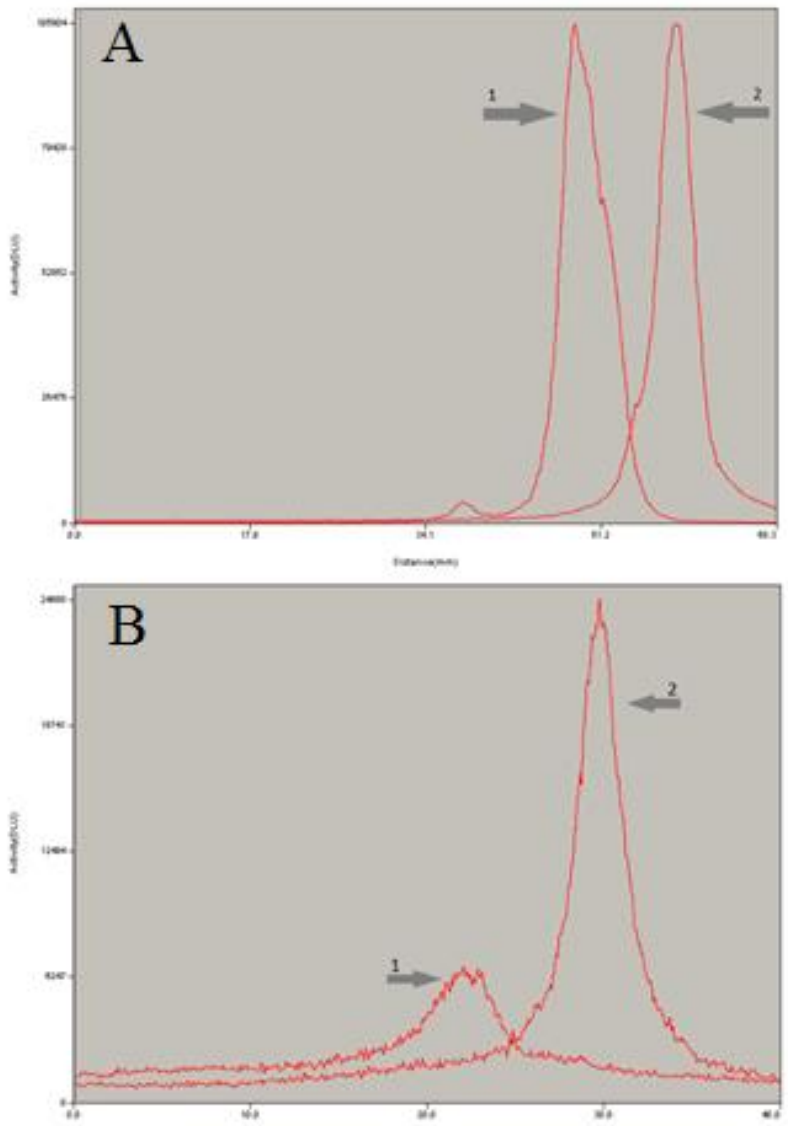

Figure S3. SDS-PAGE analysis of ${ }^{68}$ Ga-NOTA-P2-RM26 (A) and ${ }^{111}$ In-NOTA-P2-RM26 (B) after $1 \mathrm{~h}$ incubation with a 500-fold molar excess of EDTA at RT. 1 Radiolabeled samples. 2 ${ }^{68}$ Ga-gallium and ${ }^{111}$ In-indium was used as low molecular weight radioactivity marker on the same gel. 


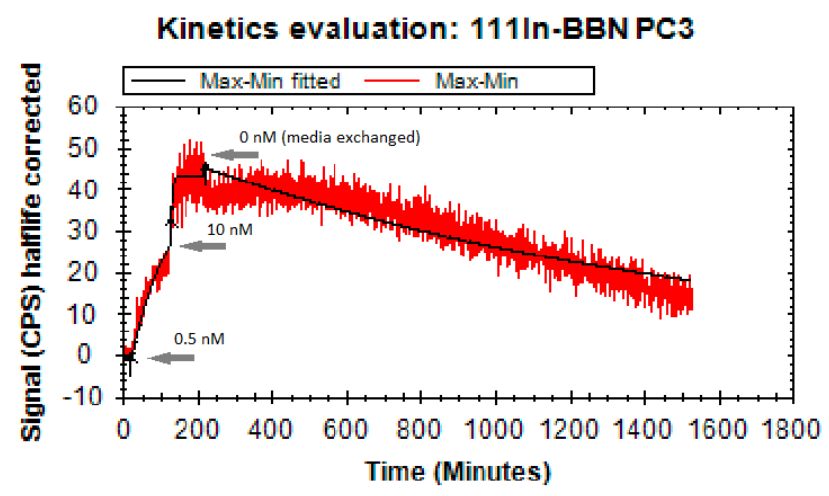

Figure S4. Real-time kinetics of peptide/cell surface receptor interactions in intact cells. Uptake (for 0.5 and $10 \mathrm{nM}$ concentrations) and cellular retention of ${ }^{111}$ In-NOTA-P2-RM26 interacting with GRPRs on PC-3 cells was monitored in real-time at room temperature. 